Old Dominion University

ODU Digital Commons

$9-2013$

Dynamical Downscaling Projections of Twenty-First-Century Atlantic Hurricane Activity: CMIP3 and CMIP5 Model-Based Scenarios

Thomas R. Knutson

Joseph J. Sirutis

Gabriel A. Vecchi

Stephen Garner

Ming Zhao

See next page for additional authors

Follow this and additional works at: https://digitalcommons.odu.edu/ccpo_pubs

Part of the Atmospheric Sciences Commons, Climate Commons, and the Meteorology Commons 


\section{Authors}

Thomas R. Knutson, Joseph J. Sirutis, Gabriel A. Vecchi, Stephen Garner, Ming Zhao, Hyeong-Seog Kim, Morris Bender, Robert E. Tuleya, Isaac M. Held, and Gabriele Villarini 


\title{
Dynamical Downscaling Projections of Twenty-First-Century Atlantic Hurricane Activity: CMIP3 and CMIP5 Model-Based Scenarios
}

\author{
Thomas R. Knutson,* Joseph J. Sirutis,* Gabriel A. Vecchi,* Stephen Garner,* Ming ZhaO,* \\ Hyeong-SeOg Kim, ${ }^{+}$Morris Bender, ${ }^{*}$ Robert E. Tuleya, ${ }^{\#}$ IsaAC M. Held, $*$ \\ AND GABRIELE VILLARINI ${ }^{@}$ \\ * NOAA/Geophysical Fluid Dynamics Laboratory, Princeton, New Jersey \\ ${ }^{+}$Program in Atmospheric and Oceanic Sciences, Princeton University, Princeton, New Jersey \\ \# Center for Coastal Physical Oceanography, Old Dominion University, Norfolk, Virginia \\ ${ }^{\circledR}$ IIHR-Hydroscience and Engineering, The University of Iowa, Iowa City, Iowa
}

(Manuscript received 27 July 2012, in final form 8 February 2013)

\begin{abstract}
Twenty-first-century projections of Atlantic climate change are downscaled to explore the robustness of potential changes in hurricane activity. Multimodel ensembles using the phase 3 of the Coupled Model Intercomparison Project (CMIP3)/Special Report on Emissions Scenarios A1B (SRES A1B; late-twenty-first century) and phase 5 of the Coupled Model Intercomparison Project (CMIP5)/representative concentration pathway 4.5 (RCP4.5; early- and late-twenty-first century) scenarios are examined. Ten individual CMIP3 models are downscaled to assess the spread of results among the CMIP3 (but not the CMIP5) models. Downscaling simulations are compared for $18-\mathrm{km}$ grid regional and 50-km grid global models. Storm cases from the regional model are further downscaled into the Geophysical Fluid Dynamics Laboratory (GFDL) hurricane model (9-km inner grid spacing, with ocean coupling) to simulate intense hurricanes at a finer resolution.

A significant reduction in tropical storm frequency is projected for the CMIP3 $(-27 \%)$, CMIP5-early $(-20 \%)$ and CMIP5-late $(-23 \%)$ ensembles and for 5 of the 10 individual CMIP3 models. Lifetime maximum hurricane intensity increases significantly in the high-resolution experiments-by $4 \%-6 \%$ for CMIP 3 and CMIP5 ensembles. A significant increase $(+87 \%)$ in the frequency of very intense (categories 4 and 5) hurricanes (winds $\geq 59 \mathrm{~m} \mathrm{~s}^{-1}$ ) is projected using CMIP3, but smaller, only marginally significant increases are projected $(+45 \%$ and $+39 \%)$ for the CMIP5-early and CMIP5-late scenarios. Hurricane rainfall rates increase robustly for the CMIP3 and CMIP5 scenarios. For the late-twenty-first century, this increase amounts to $+20 \%$ to $+30 \%$ in the model hurricane's inner core, with a smaller increase $(\sim 10 \%)$ for averaging radii of $200 \mathrm{~km}$ or larger. The fractional increase in precipitation at large radii $(200-400 \mathrm{~km})$ approximates that expected from environmental water vapor content scaling, while increases for the inner core exceed this level.
\end{abstract}

\section{Introduction}

The influence of global warming, as projected for the twenty-first century by current climate models (e.g., Solomon et al. 2007), on hurricane activity in the Atlantic basin is an important research question. Climate model projections from phase 3 of the Coupled Model Intercomparison (CMIP3; Meehl et al. 2007) and phase 5 of the Coupled Model Intercomparison (CMIP5; Taylor et al. 2012) suggest substantial $\left(\sim 1.5^{\circ} \mathrm{C}\right)$ increases over the

Corresponding author address: Thomas R. Knutson, NOAA/ Geophysical Fluid Dynamics Laboratory, 201 Forrestal Rd., Princeton, NJ 08542.

E-mail: tom.knutson@noaa.gov century in sea surface temperatures (SSTs) in the basin, while wind shear and other storm-influencing factors are projected to change as well (e.g., Vecchi and Soden 2007a,b). Therefore, a question arises as to the net impact of these various environmental influences on hurricane activity.

A related issue that arises in attempts to use statistical models to address this problem is the role of local tropical Atlantic SST versus relative SST (i.e., tropical Atlantic SST relative to the tropical mean SST) in changing Atlantic hurricane activity. Some statistical relationships linking Atlantic hurricane activity and local tropical Atlantic SSTs suggest that a substantial $\left(\sim 2^{\circ} \mathrm{C}\right)$ warming of the tropical Atlantic would lead to a large increase $(+300 \%)$ in a seasonally integrated tropical cyclone power dissipation index (PDI; Emanuel 2005, 2007) (Emanuel 2007; Vecchi 
et al. 2008). Other statistical and dynamical models and physical considerations (e.g., Latif et al. 2007; Vecchi and Soden 2007a; Swanson 2008; Bender et al. 2010; Zhao et al. 2010; Ramsay and Sobel 2011; Vecchi et al. 2008, 2011, 2013b; Villarini et al. 2011; Villarini and Vecchi 2012a; Camargo et al. 2013) suggest that the relative Atlantic SST is a more robust statistical indicator of Atlantic hurricane activity change for the types of climate perturbations relevant for both interannual variability and twenty-first-century climate change projections than local Atlantic SST. These alternative models suggest relatively much smaller $( \pm 60 \%)$ changes in Atlantic power dissipation over the coming century (Vecchi et al. 2008; Villarini and Vecchi 2013).

Recently, Villarini and Vecchi (2013) provided an updated statistical model projection based on the CMIP5 climate model projections. These new projections include an increase in Atlantic PDI across all 17 CMIP5 models and 3 representative concentration pathways (RCPs). Since the number of North Atlantic tropical cyclones is not projected to increase significantly in their analysis (Villarini and Vecchi 2012b), they attribute the increased PDI to an intensification of Atlantic tropical cyclones in response to both greenhouse gas (GHG) increases and aerosol changes over the coming decades, with a significant enhancement by non-GHG (primarily aerosol) forcing in the first half of the twenty-first century.

In previous papers (Knutson et al. 2007; Knutson et al. 2008; Bender et al. 2010), we have explored these issues using dynamical downscaling approaches. The present study is an extension of these studies, comparing projections using CMIP5 climate models to the earlier CMIP3 projections. We now include more analysis of the robustness of the CMIP3 projections (Knutson et al. 2008; Bender et al. 2010) by downscaling 10 individual CMIP3 models to explore the spread of projections among the individual models. For the CMIP5 multimodel ensemble projections, we consider both early-twenty-first-century and late-twenty-first-century projections in light of the findings of Villarini and Vecchi (2013). Individual CMIP5 models have not been examined in our experiments to date.

We use three different dynamical downscaling models in different combinations to derive our tropical cyclone projections. The first is a regional $18-\mathrm{km}$ grid atmospheric model (ZETAC; Knutson et al. 2007) nested within the National Centers for Environmental Prediction (NCEP) reanalyses (Kalnay et al. 1996). We explore climate change scenarios with this model by perturbing the reanalysis input with climate model-projected changes in large-scale circulation, temperatures, moisture, and SSTs for the late-twenty-first century (Knutson et al. 2008). In the second approach, we examine changes in Atlantic tropical storms and hurricanes (up to category 2) for the same climate change scenarios but use a $50-\mathrm{km}$ grid global atmospheric model [High-resolution Atmospheric Model (HiRAM); Zhao et al. 2009] for the downscaling. For the third approach, we downscale all of the tropical storms and hurricanes from our 18-km grid regional model, on a case-by-case basis, into the Geophysical Fluid Dynamics Laboratory (GFDL) coupled ocean-atmosphere hurricane prediction system (Bender et al. 2010) in order to simulate hurricanes with intensities up to category 4 and 5 intensity. This requires higher model resolution than in the ZETAC model to better resolve the storm's inner core.

Through these modeling studies we can explore the sensitivity of our projections to different sources of uncertainty. For example, there is uncertainty in the largescale projected climate changes that are input to the downscaling (CMIP3 versus CMIP5 multimodel ensemble projections or the range of projections among individual CMIP3 models illustrate this but probably do not span the full range of uncertainty). There is also uncertainty in the downscaling results for a given climate change scenario based on the particular model or method used for the downscaling (i.e., the ZETAC regional model versus the HiRAM 50-km-grid global model or the GFDL hurricane model versus statistical downscaling). See Table 1 for complete list of models and model expansions.

\section{Model description}

The models we use at various stages of our hurricane downscaling are summarized in Table 2. These include a regional atmospheric model for seasonal Atlantic simulations; a hurricane prediction model for a further downscaling of the individual storms in the regional atmospheric model; and several global climate models, which provide projected late-twenty-first-century climate change boundary conditions for our climate change perturbation runs. We also compare our tropical cyclone downscaling results with those from a global atmospheric model run for multiyear "time slices" of the present and projected future climate. The various CMIP3 and CMIP5 climate models and scenarios used in our study (as well as full expansions) are listed in Vecchi and Soden (2007b) and Table 3, respectively, and will be described in more detail later in this section. We assess the significance of our downscaling results using statistical significance tests for both individual model results and for experiments with multimodel ensemble climate change perturbations. These statistical tests assess the strength of the climate change signal in storm behavior relative to the modelderived internal variability (or weather noise) in our experiments. However, this weather noise is just one aspect 
TABLE 1. All CMIP models and model expansions used in this paper.

\begin{tabular}{|c|c|}
\hline Model name & Model expansion \\
\hline CanESM2 & Second Generation Canadian Earth System Model \\
\hline CCSM3 & Community Climate System Model, version 3 \\
\hline CCSM4 & Community Climate System Model, version 4 \\
\hline CNRM-CM5 & Centre National de Recherches Météorologiques Coupled Global Climate Model, version 5 \\
\hline CSIRO-Mk3.6.0 & Commonwealth Scientific and Industrial Research Organisation Mark, version 3.6.0 \\
\hline FGOALS-g2 & Flexible Global Ocean-Atmosphere-Land System Model gridpoint, second spectral version \\
\hline GFDL-CM2.0 & Geophysical Fluid Dynamics Laboratory Climate Model, version 2.0 \\
\hline GFDL-CM2.1 & Geophysical Fluid Dynamics Laboratory Climate Model, version 2.1 \\
\hline GFDL-CM3 & Geophysical Fluid Dynamics Laboratory Climate Model, version 3 \\
\hline GFDL-ESM2G & $\begin{array}{l}\text { Geophysical Fluid Dynamics Laboratory Earth System Model with Generalized Ocean Layer Dynamics } \\
\text { (GOLD) component (ESM2G) }\end{array}$ \\
\hline GFDL-ESM2M & $\begin{array}{l}\text { Geophysical Fluid Dynamics Laboratory Earth System Model with Modular Ocean Model } 4 \text { (MOM4) } \\
\text { component (ESM2M) }\end{array}$ \\
\hline HadCM3 & Hadley Centre Coupled Model, version 3 \\
\hline HadGEM1 & Hadley Centre Global Environment Model, version 1 \\
\hline HadGEM2-CC & Hadley Centre Global Environment Model, version 2 - Carbon Cycle \\
\hline HadGEM2-ES & Hadley Centre Global Environment Model, version 2 - Earth System \\
\hline INGV & Istituto Nazionale di Geofisica e Vulcanologia \\
\hline IPSL-CM5A-LR & L'Institut Pierre-Simon Laplace Coupled Model, version 5, coupled with NEMO, low resolution \\
\hline IPSL-CM5A-MR & L'Institut Pierre-Simon Laplace Coupled Model, version 5, coupled with NEMO, mid resolution \\
\hline MIROC (hires) & Model for Interdisciplinary Research on Climate, version 3.2 (high resolution) \\
\hline MIROC (medres) & Model for Interdisciplinary Research on Climate, version 3.2 (medium resolution) \\
\hline MIROC5 & Model for Interdisciplinary Research on Climate, version 5 \\
\hline MIROC-ESM & Model for Interdisciplinary Research on Climate, Earth System Model \\
\hline MIROC-ESM-CHEM & Model for Interdisciplinary Research on Climate, Earth System Model, Chemistry Coupled \\
\hline MPI-ESM-LR & Max Planck Institute Earth System Model, low resolution \\
\hline MRI-CGCM3 & Meteorological Research Institute Coupled Atmosphere-Ocean General Circulation Model, version 3 \\
\hline NorESM1-M & Norwegian Earth System Model, version 1 (intermediate resolution) \\
\hline
\end{tabular}

of the overall uncertainty: a key test of the robustness is the comparison of results between CMIP3 and CMIP5 multimodel ensembles or between different individual CMIP3 models. These comparisons assess the robustness of our results to the use of different climate models, which is probably a much greater source of uncertainty in the projections than the weather noise uncertainty for a single given model. The different downscaling approaches provide another means of assessing robustness of the projections.

\section{a. ZETAC regional Atlantic basin model}

For our present climate (control) condition, we simulate 27 seasons (1980-2006; August-October season) of Atlantic hurricane activity using an 18-km-grid regional atmospheric model designed specifically to simulate Atlantic hurricane seasonal activity (Knutson et al. 2007). This nonhydrostatic model is run without a subgrid-scale moist convection parameterization (CP), as discussed below and in Knutson et al. (2007). The model

TABLE 2. Summary of the experiments and models used for both the control (present-day) and twenty-first-century experiments.

\begin{tabular}{|c|c|c|}
\hline Model/scenario: & $\begin{array}{c}\text { CMIP3 } \\
\text { Climate change scenario }\end{array}$ & $\begin{array}{c}\text { CMIP5 } \\
\text { Climate change scenario }\end{array}$ \\
\hline $\begin{array}{l}\text { Regional climate model } \\
\text { (ZETAC); 18-km grid }\end{array}$ & $\begin{array}{l}\text { 18-member ensemble-mean climate change for } \\
\text { SRES A1B, late-twenty-first century ( } 27 \text { season } \\
\text { samples) } \\
\text { Ten individual CMIP3 models (13-season samples) }\end{array}$ & $\begin{array}{l}\text { 18-member ensemble-mean climate change } \\
\text { for RCP4.5, early and late-twenty-first-century } \\
\text { samples; ( } 27 \text { season samples) }\end{array}$ \\
\hline $\begin{array}{l}\text { Storm-following hurricane } \\
\text { model (GFDL and GFDN } \\
\text { versions); 9-km inner grid }\end{array}$ & $\begin{array}{l}\text { All tropical cyclone cases from the above } \\
\text { ZETAC runs }\end{array}$ & $\begin{array}{l}\text { All tropical cyclone cases from the above } \\
\text { ZETAC runs }\end{array}$ \\
\hline GCM: HiRAM (50-km grid) & $\begin{array}{l}\text { 18-member ensemble-mean climate change for } \\
\text { A1B, late-twenty-first century (10 repeating } \\
\text { seasonal cycles) } \\
7 \text { individual CMIP3 models are in common with } \\
\text { the CMIP3 models used with the ZETAC model }\end{array}$ & $\begin{array}{l}\text { 13-member ensemble mean for RCP4.5 late- } \\
\text { twenty-first century (10 repeating seasonal } \\
\text { cycles) }\end{array}$ \\
\hline
\end{tabular}


TABLE 3. Summary of the 18 CMIP5 (Taylor et al. 2012) GCMs used in this study with full model expansions to create the multimodel anomalies. The last two columns indicate the models for which the required data to create boundary conditions for ZETAC (SST, SLP, air temperature, relative humidity, and winds; total 18 models) and HiRAM (SST and sea ice concentration; total 13 models) were available.

\begin{tabular}{|c|c|c|c|}
\hline Modeling center (or group) & Model name & $\begin{array}{l}\text { Used in } \\
\text { ZETAC }\end{array}$ & $\begin{array}{l}\text { Used in } \\
\text { HiRAM }\end{array}$ \\
\hline Canadian Centre for Climate Modeling and Analysis & CanESM2 & $\mathrm{Y}$ & Y \\
\hline National Center for Atmospheric Research & CCSM4 & Y & - \\
\hline $\begin{array}{l}\text { Centre National de Recherches Meteorologiques/Centre Europeen } \\
\text { de Recherche et Formation Avancees en Calcul Scientifique }\end{array}$ & CNRM-CM5 & Y & $\mathrm{Y}$ \\
\hline $\begin{array}{l}\text { Commonwealth Scientific and Industrial Research Organization } \\
\text { in collaboration with Queensland Climate Change Centre of Excellence }\end{array}$ & CSIRO-Mk3.6.0 & Y & $\mathrm{Y}$ \\
\hline Chinese Academy of Sciences, Institute of Atmospheric Physics & FGOALS-g2 & $\mathrm{Y}$ & $\mathrm{Y}$ \\
\hline NOAA Geophysical Fluid Dynamics Laboratory & GFDL-CM3 & $\mathrm{Y}$ & $\mathrm{Y}$ \\
\hline NOAA Geophysical Fluid Dynamics Laboratory & GFDL-ESM2G & $\mathrm{Y}$ & $\mathrm{Y}$ \\
\hline NOAA Geophysical Fluid Dynamics Laboratory & GFDL-ESM2M & $\mathrm{Y}$ & $\mathrm{Y}$ \\
\hline Met Office Hadley Centre & HadGEM2-CC & $\mathrm{Y}$ & - \\
\hline Met Office Hadley Centre & HadGEM2-ES & $\mathrm{Y}$ & $\mathrm{Y}$ \\
\hline L'Institut Pierre-Simon Laplace & IPSL-CM5A-LR & $\mathrm{Y}$ & - \\
\hline L'Institut Pierre-Simon Laplace & IPSL-CM5A-MR & $\mathrm{Y}$ & - \\
\hline $\begin{array}{l}\text { Atmosphere and Ocean Research Institute (The University of Tokyo), } \\
\text { National Institute for Environmental Studies, and Japan Agency for } \\
\text { Marine-Earth Science and Technology }\end{array}$ & MIROC5 & $\mathrm{Y}$ & $\mathrm{Y}$ \\
\hline $\begin{array}{l}\text { Japan Agency for Marine-Earth Science and Technology, Atmosphere } \\
\text { and Ocean Research Institute (The University of Tokyo), and } \\
\text { National Institute for Environmental Studies }\end{array}$ & MIROC-ESM & $\mathrm{Y}$ & $\mathrm{Y}$ \\
\hline $\begin{array}{l}\text { Japan Agency for Marine-Earth Science and Technology, Atmosphere } \\
\text { and Ocean Research Institute (The University of Tokyo), and National } \\
\text { Institute for Environmental Studies }\end{array}$ & MIROC-ESM-CHEM & $\mathrm{Y}$ & - \\
\hline Max Planck Institute for Meteorology & MPI-ESM-LR & $\mathrm{Y}$ & $\mathrm{Y}$ \\
\hline Meteorological Research Institute & MRI-CGCM3 & $\mathrm{Y}$ & $\mathrm{Y}$ \\
\hline Norwegian Climate Centre & NorESM1-M & $\mathrm{Y}$ & $\mathrm{Y}$ \\
\hline
\end{tabular}

is forced at the lower boundary by observed SSTs and at the horizontal boundaries by NCEP reanalyses, as described in Knutson et al. (2007, 2008). This model uses interior spectral nudging (on domain zonal and meridional wavenumbers $0-2$, with a nudging time scale of $12 \mathrm{~h}$ ) to maintain the model's large-scale time-evolving solution close to the NCEP reanalysis throughout the atmosphere. The same nudging time scale is used for all seasons and experiments (control and global warming cases).

Our philosophy in using interior spectral nudging on large spatial scales only, while not using $\mathrm{CP}$ at all, is aimed at maintaining a realistic broad-scale thermodynamic state in the model while allowing resolved convection and condensation in the model to do the work on smaller scales to produce storm genesis. In our view, CP can potentially harm the genesis process. [There are some indications of this in previous studies, such as Han and Pan (2006), Gentry and Lackmann (2006), and Zhao et al. (2012).] Also many aspects of CP remain uncertain, so that our attempt aims at allowing only model-resolved convective-condensation processes to produce the storm genesis deemed appropriate. Further, the realistic interannual variability obtained with the nudged model is encouraging, particularly since we believe it is important for a model to simulate the relative occurrence of both active and inactive years reasonably well in the control simulation to form an appropriate starting point for a climate change experiment. Global models use $\mathrm{CP}$ in part to maintain a realistic mean profile, but at least in the regional model context we can utilize this alternative nudging approach. Because of computational constraints, we have not explored the sensitivity of our ZETAC model global warming results to the nudging. We are aware (Zhao et al. 2012) that tropical cyclone (TC) simulations in models are sensitive to details such as $\mathrm{CP}$ and divergence damping.

For the climate change perturbation runs, the NCEP reanalysis (i.e., the nudging target) is modified by a seasonally varying climatological change field that includes the projected changes in SST, atmospheric temperature, moisture, and winds from either the CMIP3 or CMIP5 climate models. A discussion of the methods for computing global climate model (GCM) anomalies is given in section $2 \mathrm{~d}$. The atmospheric trace gas (e.g., $\mathrm{CO}_{2}$ and $\mathrm{O}_{3}$ ) and aerosol concentrations are not perturbed in the ZETAC regional model experiments. However, the influence of these forcings is implicitly incorporated into 
the model through the three-dimensional climate change field, which is used as boundary conditions and as a nudging target for the interior of the atmospheric domain.

The methodology for identifying tropical storms in the ZETAC simulations is described in Knutson et al. (2007). Our previous analyses (e.g., Fig. 1 in Knutson et al. (2008)) have indicated that the ZETAC model reproduces the observed interannual variability of Atlantic hurricane counts over 1980-2006 quite successfully, with a correlation coefficient of 0.84 for modeled versus observed time series, although the linear trend was about $40 \%$ larger than the observed trend. Since our previous study was completed, we have subsequently extended these simulation experiments through 2008. The additional 2 years substantially overpredict Atlantic hurricane counts (which leads to a linear trend that is about a factor of 2 larger than observed, and the correlation is reduced to 0.69). We speculate that the less realistic trend in these simulations with the inclusion of the most recent years is derived from large (and presumed spurious) negative trends in NCEP reanalysis temperatures, from the upper troposphere to about $100 \mathrm{hPa}$ (Vecchi et al. 2013a). Owing to our concerns about the trend component, it is useful to examine other aspects of the interannual variability. For example, if we remove the linear trend from both modeled and observed hurricane counts, the correlation between the two detrended time series is 0.63 for $1980-2008$ or 0.81 for the shorter time period (1980-2006). This indicates that the model simulates the nontrend component of variability fairly well, although with poorer agreement for the latest years of 2007 and 2008. Further details on the ZETAC model runs and their use in these experiments are provided in Knutson et al. (2007, 2008).

For the climate change runs, the same interannual variability is present as for the control run, since we add an August-October mean climate change perturbation, which does not change from year to year, onto the NCEP reanalyses that are used as the nudging target and boundary conditions. This procedure keeps unchanged the large-scale interannual-to-multidecadal variations in the interior as well as the high-frequency weather variability imposed at the model boundaries. The method avoids some difficulties in the direct use of climate model simulations, which have known biases (e.g., typically a failure to produce intense hurricanes or realistic hurricane eyewall structure due to their coarse resolution) that can distort tropical storm simulations. It further assumes that the atmospheric variability on the large (interior) scales and in the boundary conditions of our control simulation is also representative of variability conditions under the global warming scenario. For example, the occurrence frequency and amplitude of individual
El Niño-Southern Oscillation (ENSO) events are unchanged from the observed data (1980-2006) in our climate change runs.

\section{b. GFDL hurricane model}

Two versions of the GFDL hurricane model are used to resimulate at higher resolution the individual storm cases in this study. These model versions are the same as those used in Bender et al. (2010) and include the version used operationally from 2006 through 2012 at the U.S. National Weather Service (NWS; termed the GFDL hurricane model) and the version that has been used by the U.S. Navy, upgraded in 2008 (termed the GFDN hurricane model). In terms of specific differences between the two model versions, the GFDN version allows shortwave radiation penetration into the ocean, has a reduced enthalpy exchange coefficient that is in better agreement with observations, includes a minor bug fix in the coupler interpolator, and has a minor change in the randomized component of the CP scheme. These changes were not implemented in the NWS version since that model was operationally frozen for several years.

The hurricane model is a triply nested moveable mesh regional atmospheric model coupled to the threedimensional Princeton Ocean Model (Bender et al. 2007). The $5^{\circ}$ latitude by $5^{\circ}$ longitude inner nest of the atmospheric model has a horizontal grid spacing of about $9 \mathrm{~km}$ and is automatically relocated to follow the moving tropical cyclone of interest. The ocean coupling provides an important physical process for the simulations, as it allows the tropical cyclone to interact with the ocean and generate a cold wake in the SSTs, which can in turn affect the cyclone's intensity. We used the 18-model average three-dimensional ocean structure change from the CMIP3 models to represent the change in ocean temperature stratification in the warmer climate for all of the hurricane model climate change experiments. Preliminary sensitivity experiments (not shown) indicated that the hurricane model results are relatively insensitive to the details of projected changes in the ocean subsurface temperature profile (see also Knutson et al. 2001).

Each individual tropical storm and hurricane case from the ZETAC regional model was downscaled using the two versions of the hurricane model discussed above. We first identified the time of maximum intensity of the storm in the ZETAC model and then backed up 3 days from that point to begin the 5-day hurricane model integration. This approach tends to preclude looking at integrated storm statistics (such as PDI) in the hurricane model, since only part of the storm lifetime is simulated. Similarly, landfalling statistics are also not well captured. We plan to conduct longer (15 day) integrations 
of the hurricane model in future studies, if possible, to address some of these issues.

\section{c. HiRAM C180 global model}

To explore the dependence of the tropical storm and hurricane frequency change projections on the model used for downscaling, we compare the ZETAC 18-km grid regional model projections to those from a $50-\mathrm{km}$ grid global atmospheric model. The global model (termed HiRAM C180) is described in Zhao et al. (2009) along with the method of identifying tropical storms in the model simulations. As shown in Zhao et al. (2009), the model realistically simulates the interannual variability of Atlantic hurricane frequency when forced by observed SSTs alone. Other aspects of the simulations from this atmospheric model, such as the simulated mean climate, are described in I. Held et al. (2013, unpublished manuscript). Here, the control run is based on 10 repeating seasonal cycles using the observed climatology of SST and sea ice. The climate warming experiments with the model again include 10 repeating seasonal cycles, but use the observed climatology modified by changes to SST and sea ice concentration fields. For the CMIP3 experiments, the changes are based on linear trends (2001-2100) from an ensemble of GCMs (Meehl et al. 2007) scaled to an 80-yr equivalent change (see section 2d). The forcing change consists of an increase in $\mathrm{CO}_{2}$ to $720 \mathrm{ppm}$, with no changes to other climate forcing agents such as aerosols. In the warmclimate runs, the nonnegligible effect of an increase in $\mathrm{CO}_{2}$ in isolation, with prescribed SSTs (roughly a $20 \%$ reduction in both Atlantic tropical cyclones and hurricanes), is described in Held and Zhao (2011).

A second multimodel ensemble forcing experiment was performed using the CMIP5 models. For the CMIP5 runs with the HiRAM model, all greenhouse gases are modified according to the $4.5 \mathrm{~W} \mathrm{~m}^{-2} \mathrm{RCP} 4.5$ scenario. Since both the CMIP3 and CMIP5 sets of model experiments are based on 10-yr samples (control and latetwenty-first century) using a repeating season cycle, the runs do not include interannual variations such as ENSO. This procedure differs from the procedure used for the ZETAC regional model climate change runs (section 2a).

\section{d. Global climate model projections}

We use large-scale climate-change projections from global climate models as boundary conditions in these downscaling studies. For the HiRAM C180 global model experiments, we use only the change in SST and sea ice concentrations from the global climate models (which are computed separately for each month of the seasonal cycle), as well as an increase in $\mathrm{CO}_{2}$ (CMIP3 runs) or all greenhouse gases (CMIP5 runs). For the ZETAC regional model late-twenty-first-century experiments, we use changes in SST, sea level pressure (SLP), air temperature, relative humidity, and wind velocity to modify the NCEP reanalysis fields that are used as boundary forcing and as the nudging target for the interior spectral nudging procedure (section 2a).

For our CMIP3-based experiments with both ZETAC and HiRAM-C180, we use either an ensemble average of 18 different CMIP3 models or individual CMIP3 models. For this study, we tested 10 of the 18 individual models. For the 10 individual CMIP3 models, we performed the ZETAC model downscaling for only the 13 odd years (1981-2005) in order to save computing resources.

The 10 selected individual CMIP3 models were chosen from among the 12 highest-ranking models according to a multivariate performance index for twentiethcentury historical forcing runs (Reichler and Kim 2008). Because of issues with the archived humidity data that are required for our experiments, 2 of the 12 highestranking models were not included in our set. We did not attempt to test all 18 models for this study because of computational and time limitations. The 10 individual CMIP3 models are shown in Fig. 1. The 18 models comprising the multimodel ensemble are listed in Vecchi and Soden (2007a). For the 18-model ensemble, we used the August-October time average of the years 2081-2100 minus the August-October time average for 2001-20 [Special Report on Emissions Scenarios A1B (SRES A1B) scenario] as the time-invariant three-dimensional climate change perturbation. When using individual models, we first computed the linear trend through the model fields for 2001-2100, project the model data onto these linear trends, and then compute the difference 2081-2100 minus 2001-20 of the linear trend projection of the fields as the climate change perturbation. This procedure helps to reduce the contamination of the model climate change signal by the models' internal variability (Knutson et al. 2008).

For our CMIP5 experiments, we use data from a second 18-model ensemble based on the RCP4.5 scenario (Table 3). Because of differing data requirements for ZETAC and HiRAM and because of limited availability of sea ice concentration data, we were limited to exploring a 13-model ensemble average with HiRAM, while with ZETAC we were able to explore the full 18model ensemble average. For the CMIP5 models, anomalies were computed as the difference between either the period 2016-35 or 2081-2100 of the RCP4.5 scenario and the baseline years of 1986-2005 from the historical climate simulations (which is an earlier baseline period, and hence a longer period between averaging periods, than we used for CMIP3). The global surface temperature difference for our climate change perturbation is quite similar for our CMIP3 and CMIP5 runs $\left(1.69^{\circ}\right.$ versus 

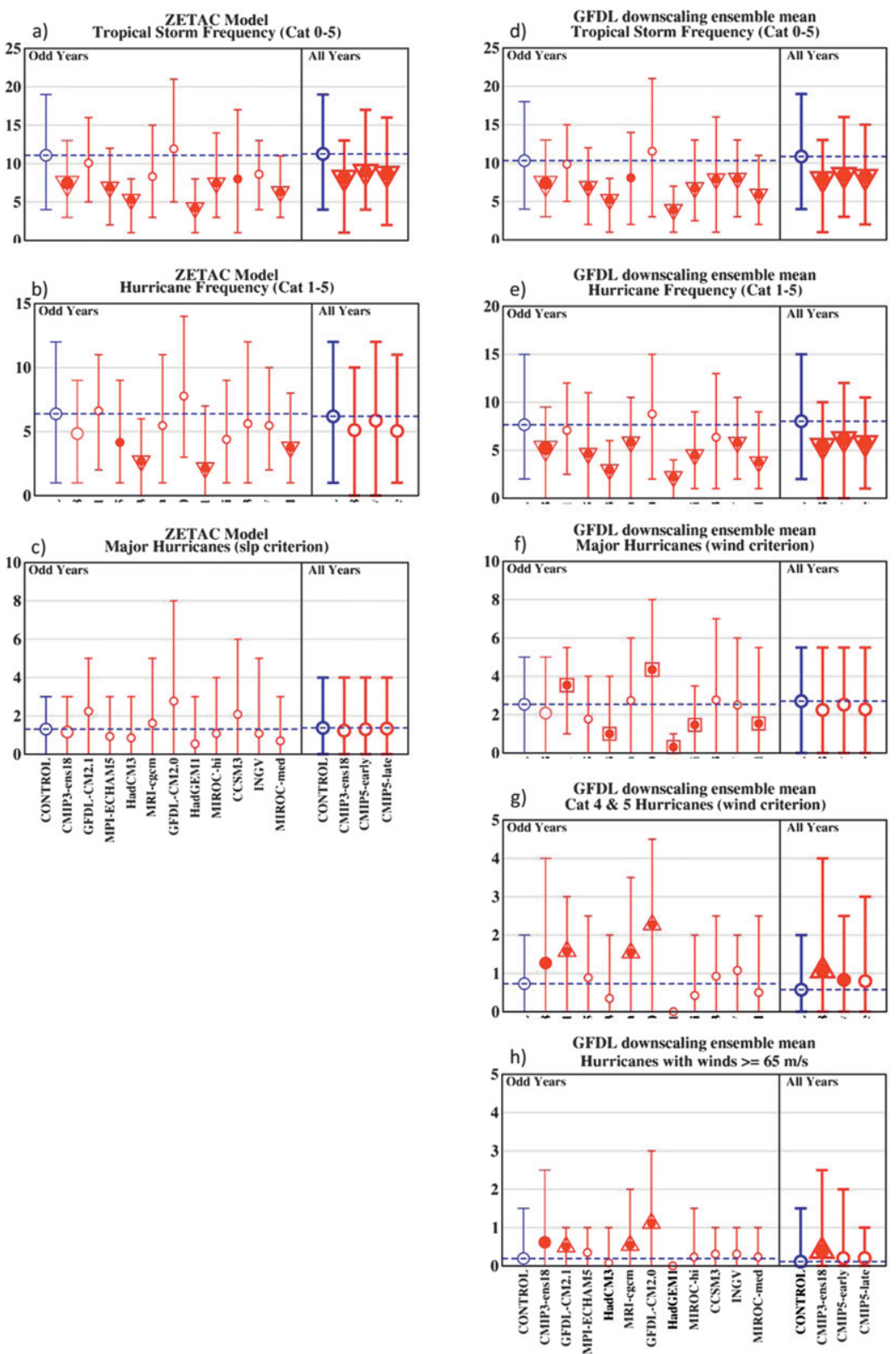

FIG. 1. Means (circles, triangles, or boxes) and ranges (vertical lines) across all simulated years of storm counts for each model experiment. Filled circles and open triangles indicate where the change between the present-day (control) run and warm-climate storm frequency is statistically significant $(p<0.05)$, according to a two-sample one-sided $t$ test (filled circle) or a one-sided Mann-Whitney-Wilcoxon median test (triangles). The sign of the one-sided test used is indicated by the direction of the triangles. The words "Odd Years" at the top of the panels refer to the 13 (August-October) seasons simulated for the individual CMIP3 models. The words "All Years" refer to the 27 (August-October) seasons simulated for the 18-model ensemble CMIP3 and CMIP5 climate changes. Results were obtained by (left) downscaling using the ZETAC regional model or (right) using the ZETAC model followed by a second downscaling step applied to each storm case using the GFDL hurricane model. Results are shown for up to five classes of storm intensity: (a), (d) tropical storms and hurricanes; (b),(e) hurricanes; (c),(f) major hurricanes, category 3-5 (for major hurricanes, boxes are used instead of triangles, as two-sided tests were performed for these cases); (g) category 4-5 hurricanes; and (h) strong category 4+ hurricanes with maximum winds exceeding $65 \mathrm{~m} \mathrm{~s}^{-1}$. The GFDL model results in (d)-(h) are based on a two-member ensemble for each case using two versions of the GFDL hurricane model (GFDL and GFDN). Major hurricanes from the ZETAC model are diagnosed in (c) using central pressure rather than maximum winds. 
TABLE 4. Storm statistics from CMIP5- vs CMIP3-based downscaling experiments for Atlantic tropical storms and hurricanes, based on comparing 27 August-October seasons (1980-2006) with and without a climate change perturbation. CMIP3 and CMIP5 refer to storm climate changes simulated using climate change information from the CMIP3-A1B and CMIP5-RCP4.5 multimodel ensembles. CMIP5-early and CMIP5-late perturbations are for years 2016-35 and 2081-2100, respectively, compared to the historical simulations (years 1986-2005). Control refers to our present-day downscaling simulations (1980-2006). The hurricane model results are for the average of runs using two model versions (GFDL and GFDN). Hur refers to hurricane; Ts refers to tropical storms and hurricanes combined. Frequencies are in number per year (August-October only). Cat is Saffir-Simpson intensity category (1-5) with cat 0 signifying less than hurricane strength. Trans speed is storm translation speed in $\mathrm{m} \mathrm{s}^{-1}$. Rain rate is the average rain rate within $100 \mathrm{~km}$ of the storm center in $\mathrm{mm} \mathrm{day}^{-1}$. PDI is in units of $10^{9} \mathrm{~m}^{3} \mathrm{~s}^{-2}$. Hur_ws $>65$ refers to hurricanes with surface wind speeds $\geq 65 \mathrm{~m} \mathrm{~s}^{-1}$. Maxwnd_ts and maxwnd_hur are mean lifetime maximum intensities for all tropical storms (wind speed $>17.5 \mathrm{~m} \mathrm{~s}^{-1}$ ) or hurricanes (wind speed $>33 \mathrm{~m} \mathrm{~s}^{-1}$ ). For the statistical adjustment method, there were no category 5 hurricanes in the control or for either of the CMIP5 ensembles; there were five category 5 hurricanes in the CMIP3-A1B ensemble results ( 0.185 storms per year). The $p$ levels in parentheses are the estimated probabilities of incorrectly rejecting the null hypothesis of no change in the metric, based on one-sided Mann-Whitney-Wilcoxon tests. Two-sided tests were used for translation speed, Hur (3-5), and Hur (Cat 3 ) statistics. One-sided tests were used for other metrics; these $p$ values can be converted to two-sided results by multiplying the $p$ value by 2. Bold highlights changes that are significant at the 0.05 level.

\begin{tabular}{|c|c|c|c|c|c|}
\hline \multirow[b]{3}{*}{ Variable } & \multirow{2}{*}{\multicolumn{2}{|c|}{ Means }} & \multicolumn{3}{|c|}{ ZETAC regional model } \\
\hline & & & \multicolumn{3}{|c|}{$\%$ change ( $p$ level) } \\
\hline & Obs & Control & CMIP3 & CMIP5-early & CMIP5-late \\
\hline Ts $(0-5)$ frequency & 9.00 & 11.26 & $-27.3(<0.01)$ & $-20.4(0.02)$ & $-22.7(0.02)$ \\
\hline Hur (1-5) frequency & 5.30 & 6.19 & $-17.4(0.15)$ & $-5.4(0.36)$ & $-18.6(0.08)$ \\
\hline PDI & 235.33 & 179.12 & $-21.1(0.04)$ & $-21.0(0.05)$ & $-23.3(0.03)$ \\
\hline Maxwnd_ts & 39.44 & 34.13 & $3.5(0.05)$ & $2.4(0.07)$ & $2.9(0.04)$ \\
\hline Maxwnd_hur & 49.57 & 38.76 & $2.0(0.05)$ & $-0.7(0.14)$ & $2.2(0.04)$ \\
\hline Landfall_ts & 2.37 & 2.19 & $-16.9(0.27)$ & $18.6(0.10)$ & $3.4(0.46)$ \\
\hline Landfall_hur & 1.04 & 0.96 & $-23.1(0.38)$ & $3.8(0.36)$ & $-11.5(0.40)$ \\
\hline Trans speed & 6.64 & 6.38 & $2.1(0.27)$ & $-4.7(0.03)$ & $-1.9(0.26)$ \\
\hline Rain rate_ts & - & 185.99 & $18.8(<0.01)$ & $7.8(0.04)$ & $13.4(<0.01)$ \\
\hline Rain rate_hur & - & 278.15 & $16.7(<0.01)$ & $3.1(0.34)$ & $9.0(0.02)$ \\
\hline Ts (cat 0$)$ & 3.70 & 5.1 & $-39.4(<0.01)$ & $-38.7(<0.01)$ & $-27.7(0.02)$ \\
\hline Hur (cat 1) & 1.89 & 5.41 & $-25.3(0.05)$ & $-2.7(0.46)$ & $-23.3(0.05)$ \\
\hline Hur (cat 2) & 1.04 & 0.78 & $38.1(0.11)$ & $-23.8(0.49)$ & $14.3(0.15)$ \\
\hline
\end{tabular}

\begin{tabular}{|c|c|c|c|c|c|}
\hline \multirow[b]{3}{*}{ Variable } & & & \multicolumn{3}{|c|}{ Hurricane model downscale } \\
\hline & \multicolumn{2}{|c|}{ Means } & \multicolumn{3}{|c|}{$\%$ change ( $p$ level) } \\
\hline & Obs & Control & CMIP3 & CMIP5-early & CMIP5-late \\
\hline Ts $(0-5)$ frequency & 9.00 & 10.85 & $-27.0(<0.01)$ & $-22.0(<0.01)$ & $-24.2(<0.01)$ \\
\hline Hur (1-5) frequency & 5.30 & 8.02 & $-31.9(<0.01)$ & $-23.1(<0.01)$ & $-28.2(<0.01)$ \\
\hline Hur $(3-5)$ & 2.37 & 2.70 & $-17.1(0.17)$ & $-6.8(0.63)$ & $-15.8(0.25)$ \\
\hline Hur (4-5) & 1.37 & 0.57 & $87.1(0.01)$ & $45.2(0.06)$ & $38.7(0.11)$ \\
\hline Hur_ws $>65$ & 0.52 & 0.11 & $250.0(0.05)$ & $83.3(0.25)$ & $83.3(0.17)$ \\
\hline PDI & 235.33 & 183.05 & $-17.2(0.04)$ & $-12.3(0.09)$ & $-20.1(0.02)$ \\
\hline Maxwnd_ts & 39.44 & 41.12 & $0.7(0.20)$ & $3.4(0.04)$ & $1.7(0.18)$ \\
\hline Maxwnd_hur & 49.57 & 46.09 & $6.1(<0.01)$ & $4.5(<0.01)$ & $4.0(0.02)$ \\
\hline Trans speed & 6.64 & 5.57 & $6.0(0.22)$ & $-3.0(0.23)$ & $-2.0(0.31)$ \\
\hline Rain rate_ts & - & 160.88 & $22.1(<0.01)$ & $18.2(<0.01)$ & $19.2(<0.01)$ \\
\hline Rain rate_hur & - & 226.17 & $22.1(<0.01)$ & $11.4(<0.01)$ & $21.6(<0.01)$ \\
\hline Ts (cat 0$)$ & 3.70 & 2.83 & $-13.1(0.10)$ & $-19.0(0.04)$ & $-13.1(0.07)$ \\
\hline Hur (cat 1) & 1.89 & 3.41 & $-51.6(<0.01)$ & $-41.3(<0.01)$ & $-43.5(<0.01)$ \\
\hline Hur (cat 2) & 1.04 & 1.91 & $-17.5(0.17)$ & $-13.6(0.23)$ & $-18.4(0.10)$ \\
\hline Hur (cat 3) & 1.00 & 2.13 & $-45.2(<0.01)$ & $-20.9(0.10)$ & $-30.4(0.01)$ \\
\hline Hur (cat 4) & 1.00 & 0.56 & $83.3(0.01)$ & $46.7(0.05)$ & $30.0(0.21)$ \\
\hline Hur (cat 5) & 0.37 & 0.02 & $200.0(0.37)$ & $0.0(-)$ & $300.0(0.31)$ \\
\hline
\end{tabular}

\begin{tabular}{|c|c|c|c|c|c|}
\hline \multirow[b]{3}{*}{ Variable } & & & \multicolumn{3}{|c|}{ Statistical refinement } \\
\hline & \multicolumn{2}{|c|}{ Means } & \multicolumn{3}{|c|}{$\%$ change ( $p$ level) } \\
\hline & Obs & Control & CMIP3 & CMIP5-early & CMIP5-late \\
\hline Ts $(0-5)$ frequency & 9.00 & 11.26 & $-27.3(<0.01)$ & $-20.4(0.02)$ & $-22.7(0.02)$ \\
\hline Hur (1-5) frequency & 5.3 & 7.41 & $-24.0(0.04)$ & $-14.5(0.15)$ & $-19.0(0.07)$ \\
\hline
\end{tabular}


TABLE 4. (Continued)

\begin{tabular}{|c|c|c|c|c|c|}
\hline \multirow[b]{3}{*}{ Variable } & \multirow{2}{*}{\multicolumn{2}{|c|}{ Means }} & \multicolumn{3}{|c|}{ Statistical refinement } \\
\hline & & & \multicolumn{3}{|c|}{$\%$ change ( $p$ level) } \\
\hline & Obs & Control & CMIP3 & CMIP5-early & CMIP5-late \\
\hline Hur (3-5) & 2.37 & 2.89 & $-10.3(0.36)$ & $-23.1(0.15)$ & $-11.5(0.38)$ \\
\hline Hur (4-5) & 1.37 & 0.78 & $42.9(0.10)$ & $-19.0(0.48)$ & $14.3(0.15)$ \\
\hline Hur_ws $>65$ & 0.52 & 0.15 & $200.0(0.07)$ & $-25.0(0.59)$ & $125.0(0.22)$ \\
\hline PDI & 235.33 & 257.78 & $-15.6(0.09)$ & $-19.1(0.09)$ & $-20.1(0.07)$ \\
\hline Maxwnd_ts & 39.44 & 39.81 & $6.7(0.05)$ & $3.8(0.08)$ & $5.2(0.05)$ \\
\hline Maxwnd_hur & 49.57 & 46.33 & $6.2(0.02)$ & $1.5(0.46)$ & $4.1(0.06)$ \\
\hline Landfall_ts & 2.37 & 2.18 & $-17.0(0.27)$ & $18.6(0.10)$ & $3.4(0.46)$ \\
\hline Landfall_hur & 1.04 & 1.07 & $-27.6(0.26)$ & $31.0(0.12)$ & $-3.4(0.40)$ \\
\hline Ts $($ cat 0$)$ & 3.70 & 3.85 & $-33.7(<0.01)$ & $-31.7(0.02)$ & $-29.8(0.02)$ \\
\hline Hur (cat 1 ) & 1.89 & 2.96 & $-37.5(0.02)$ & $-20.0(0.12)$ & $-27.5(0.08)$ \\
\hline Hur (cat 2) & 1.04 & 1.56 & $-23.8(0.19)$ & $11.9(0.28)$ & $-16.7(0.26)$ \\
\hline Hur (cat 3) & 1.00 & 2.11 & $-29.8(0.05)$ & $-24.6(0.08)$ & $-21.1(0.10)$ \\
\hline Hur (cat 4) & 1.00 & 0.78 & $19.0(0.21)$ & $-19.0(0.48)$ & $14.3(0.15)$ \\
\hline Hur (cat 5) & 0.37 & 0.00 & (see caption) & - & - \\
\hline
\end{tabular}

$1.70^{\circ} \mathrm{C}$, respectively). Our modified approach for CMIP5 allows us to more readily explore projected changes from present climate conditions to either the early-twenty-first (2016-35) or late-twenty-first (2081-2100) century. This approach was adopted since earlier work (Villarini and Vecchi 2012b, 2013) suggested that the projected TC changes may not evolve linearly over the twenty-first century. We have not yet performed the downscaling procedure on individual climate models from the CMIP5 archive because of computational and time limitations for the present study.

\section{Results}

\section{a. Storm frequency changes}

\section{1) CMIP3 DOWNSCALING EXPERIMENTS}

The robustness of twenty-first-century model projections of tropical storm and hurricane frequency changes from either the ZETAC 18-km grid regional model (Figs. 1a-c) or the GFDL hurricane model (Figs. 1d-h) is explored in Fig. 1. By comparing the results for different models or the CMIP3 versus CMIP5 multimodel ensembles, and through statistical significance testing of these results, the robustness of our findings can be better assessed. Results are grouped by intensity class of storm, with the weakest storms included in the top panels of the figure (which show all storms of at least tropical storm intensity or maximum surface winds of at least $17 \mathrm{~m} \mathrm{~s}^{-1}$ ) and the most intense storms shown in the bottom panel of the figure.

A striking feature of Fig. 1 is the preponderance of negative changes in the occurrence (i.e., reduced frequency) of weaker storms in the warmer climate, which then shifts systematically to a preponderance of positive changes (increased frequency) for the strongest storms (e.g., category 4 and 5 storms with winds of at least $59 \mathrm{~m} \mathrm{~s}^{-1}$ or strong category $4+$ storms with winds exceeding $65 \mathrm{~m} \mathrm{~s}^{-1}$ ). This shift is much more apparent for the hurricane model results (Figs. 1d-h) than for the ZETAC regional model (Figs. 1a-c), which does not simulate high-intensity (categories 4 and 5) storms.

Tables 4 and 5 summarize these projected changes for the various classes of storms. Table 4 shows results for the 18-model CMIP3 ensemble based on 27-yr samples, whereas Table 5 focuses on results for individual CMIP3 models and examines only the 13 odd years in the sample. While CMIP3 multimodel ensemble results for the 13 odd years are shown in Table 5 for completeness, the multimodel ensemble results in Table 4 are emphasized here since they include a larger sample (all 27 seasons or years). For the CMIP3 18-model ensemble-mean climate change projection, the ZETAC regional model simulates a significant ( $p$ value $<0.01$ ) $27 \%$ reduction in tropical storm frequency (Table 4). The range across the $10 \mathrm{in}-$ dividual CMIP3 models was $-62 \%$ to $+8 \%$ (Table 5 ), with 5 of the 10 individual models showing a significant $(p<$ $0.05)$ decrease. The average of the 10 individual models (not shown) is a decrease of $30 \%$ or comparable to the simulated decrease $(-33 \%)$ for the 13 odd years using the 18-model average climate change perturbation.

For hurricane frequency in the ZETAC model, the 18model ensemble CMIP3 change is $-17 \%$ (Table 4 ), though not statistically significant $(p=0.15)$. The range across the 10 individual CMIP3 models for hurricane frequency (Table 5 ) is $-66 \%$ to $+22 \%$ with 3 of the 10 models showing a significant $(p<0.05)$ decrease. There is little significant change (Fig. 1) in major hurricanes in the ZETAC model (category 3-5 hurricanes, based on a central pressure criterion of less than $965 \mathrm{hPa}$ ). 

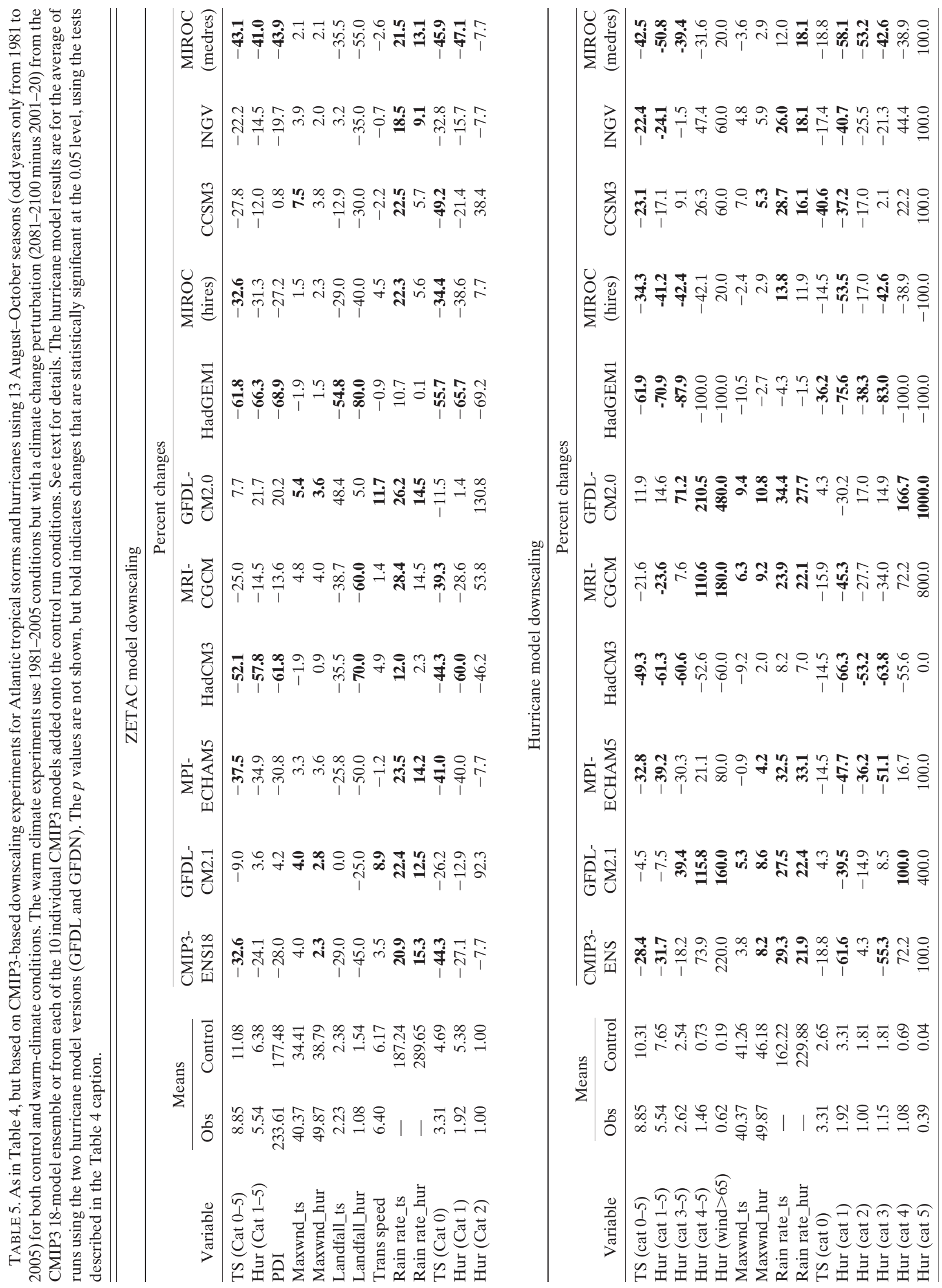
For the more intense classes of hurricanes, we focus on dynamical downscaling results from the GFDL hurricane model (ensemble of GFDL and GFDN model versions), as shown in Figs. 1f-h. The hurricane models' frequency projections for major hurricanes (category 3-5) are summarized as follows: no significant change $(-17 \%)$ for the 18-model ensemble climate change (Table 4), with a significant decrease (increase) for 4 (2) of the 10 individual CMIP3 models (Table 5). The average change for the 10 individual CMIP3 models ( $-13 \%$, not shown) is not significant, and the range across the individual models is $-88 \%$ to $+71 \%$.

For category 4 and 5 storms, a significant increase in frequency $(+87 \%$ with a p value of 0.01$)$ is simulated for the warmer climate using the 18-model ensemble-mean CMIP3 model climate change, as was shown in Bender et al. (2010). For the 10 individual models (Table 5), the range of category 4 and 5 frequency changes is $-100 \%$ to $+210 \%$, with 3 of the 10 model downscalings showing a significant $(p<0.05)$ increase.

Strong category $4+$ hurricanes with winds exceeding $65 \mathrm{~m} \mathrm{~s}^{-1}$ occur about once per decade in the control run compared with about once every 2 years in the observations (Table 4). The frequency of these storms increases significantly $(+250 \% ; p=0.05)$ for the 18 -model ensemble-mean CMIP3 climate change. The change for the average of the 10 individual CMIP3 models is $+90 \%$ but not statistically significant (not shown). The 10 individual models (Table 5) show a range of changes of $-100 \%$ to $+480 \%$, with 3 of the 10 individual models showing a significant increase. The Atlantic basin PDI shows a strong tendency for decreases in the ZETAC model (Tables 4, 5), as expected based on the basinwide changes in the various hurricane categories. While the projected changes in U.S. landfalling tropical storm and hurricane counts tend to be negative in the individual CMIP3 model experiments, the decreases in the CMIP3 ensemble-mean climate change scenario were not statistically significant.

As an alternative to the second dynamical downscaling step using the hurricane model, we also applied a statistical refinement for hurricane intensity directly to the ZETAC regional model data (Zhao and Held 2010). This statistical refinement is based on matching the percentiles of the model's control run distribution to the observed wind speed distribution, which substantially lowers the wind speed threshold used to identify highercategory hurricanes in the model. The results using this alternative approach (Table 4) show a similar overall behavior to that from dynamical downscaling using the GFDL hurricane model-at least for the frequency of weak storms. However, a statistically less robust increase in the frequency of stronger storms is projected using the statistical refinement approach, compared to dynamical downscaling (Table 4).

The downscaling projections for the frequency of Atlantic tropical storms and hurricanes for the CMIP3 and CMIP5 ensemble-mean climate change and individual CMIP3 models can also be compared between the ZETAC regional model and the GFDL HiRAM C180 global climate model (Fig. 2). The scatterplot comparison in Fig. 2 was done for the subset of CMIP3 models that are common to the experiments done with these two downscaling models. The HiRAM C180 model (50-km grid) uses prescribed SST changes from the CMIP models. In contrast, the ZETAC model is additionally forced by atmospheric temperature, wind, and moisture changes; these are internally generated by the $\mathrm{C} 180$ model. The 18-model ensemble and 7 of the 10 individual models were in common among the downscaling experiments currently available using these two downscaling models.

For tropical storms in the $\mathrm{C} 180$ experiments, all seven individual CMIP3 models and the 18-model ensemble climate change show reduced frequency, compared to the ZETAC experiments, where six of the seven individual models and the 18-model ensemble show a decrease. The correlation between the seven individual CMIP3 model percent change results is 0.77 . For hurricanes, five of the seven individual CMIP3 models and the 18-model ensemble yield a decrease in frequency using C180, while four of the seven individual models plus the 18-model ensemble show a decrease in frequency for ZETAC. If we look for consistency of hurricane downscaling response for individual CMIP3 models, only one of the seven models shows an increase in hurricane frequency in both the $\mathrm{C} 180$ and ZETAC downscaling experiments (upper right quadrant) while three show a decrease in both (lower left quadrant). Still, the correlation among the individual model percent change values is 0.73 for the hurricane changes.

\section{2) CMIP5 VERSUS CMIP3 RESULTS}

As a test of the robustness of our results to the use of the new CMIP5 climate models, we have downscaled an 18-model ensemble climate change scenario obtained from the CMIP5 models (early- and late-twenty-firstcentury projections). We have not yet had the opportunity to examine individual climate model downscalings for the CMIP5 models. The ensemble results for storm frequency are summarized and compared graphically in Figs. 1 and 2 and summarized in tabular form in Table 4. Figure 1 shows that the basic result from CMIP3 of a significant decrease in the frequency of tropical storms and hurricanes is robustly reproduced using the independent CMIP5 climate change scenarios (early- and latetwenty-first century). In terms of quantitative comparison 
a)

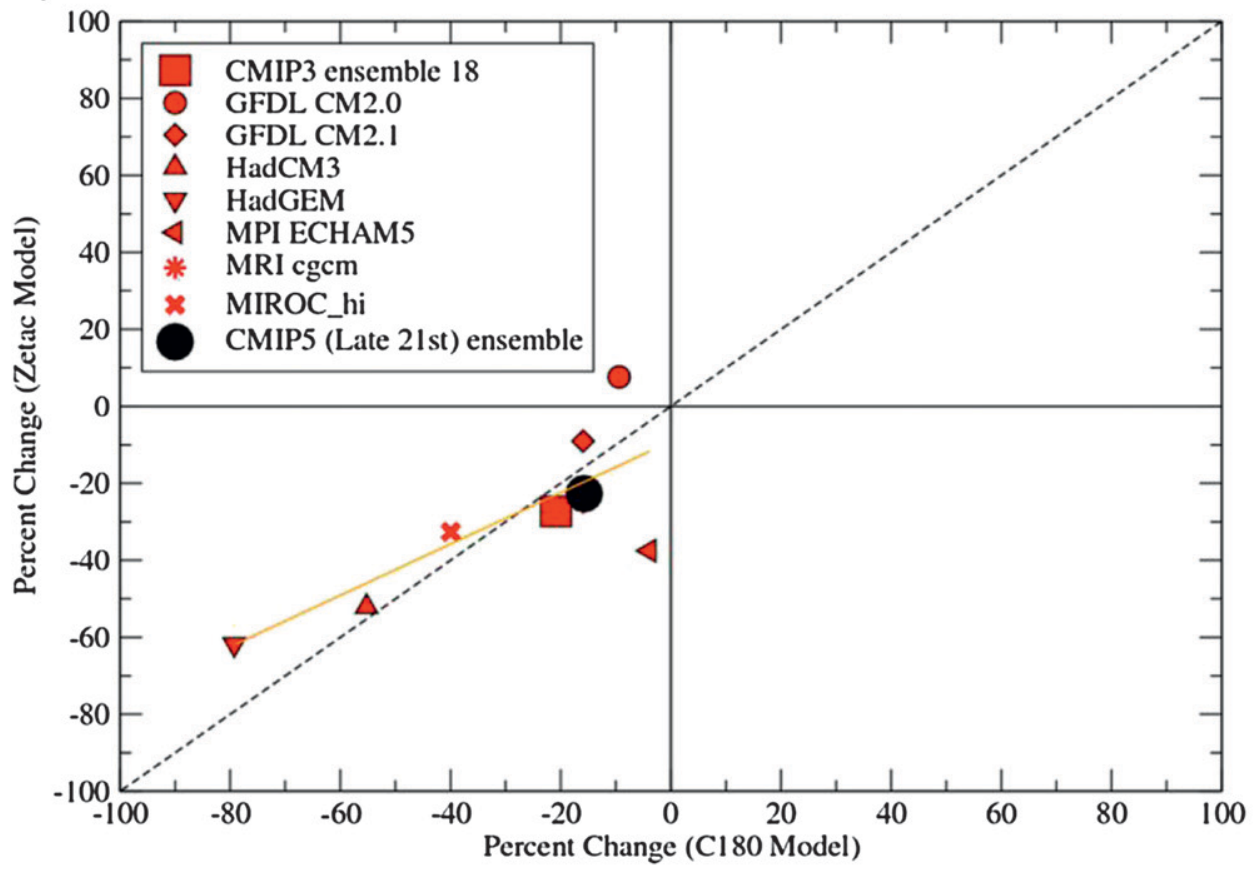

b)

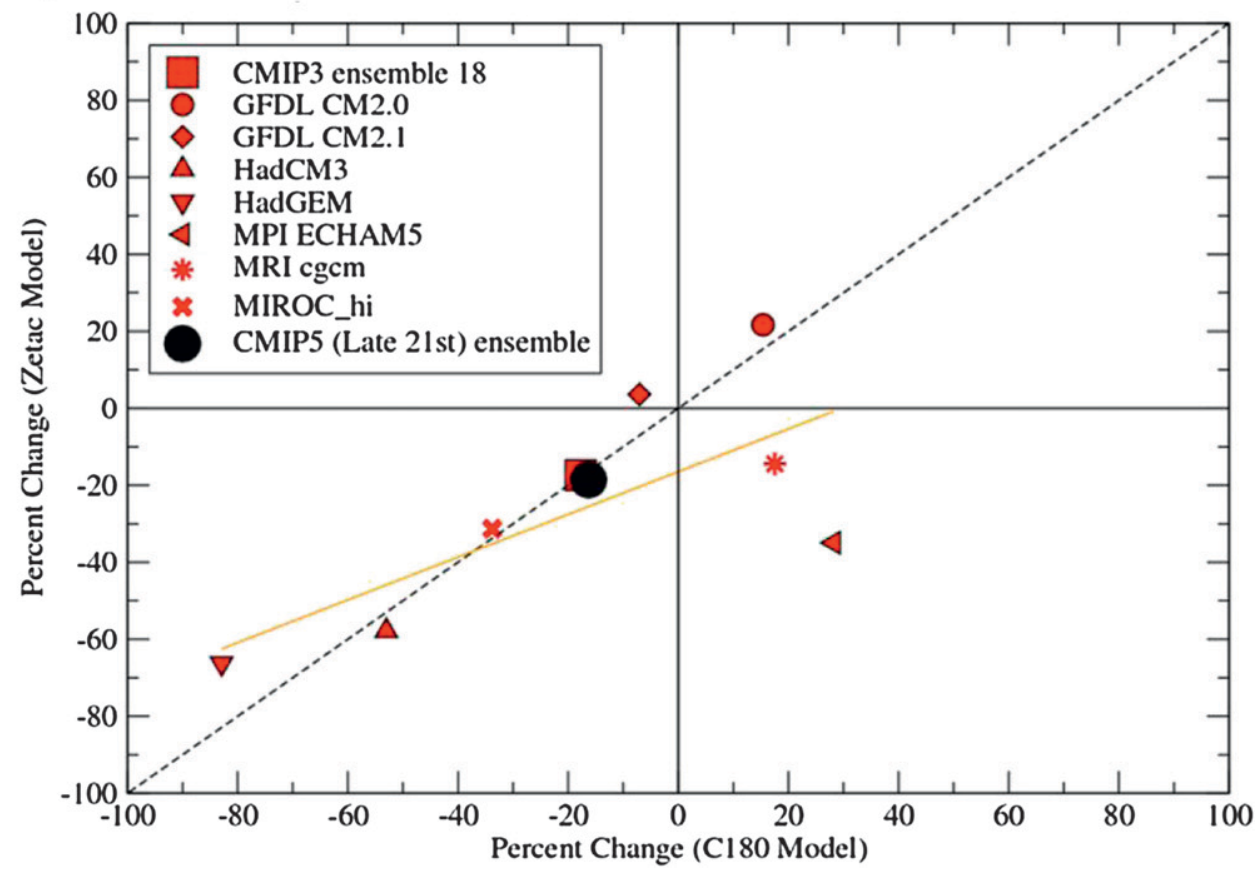

FIG. 2. Comparison of percent changes in frequency of (a) tropical storms and hurricanes (category 0-5) and (b) hurricanes (categories 1-5) for the ZETAC regional model experiments vs the HiRAM C180 global model projections (August-October season) for the late-twenty-first century. Results are shown for the CMIP3-A1B and CMIP5-RCP4.5 multimodel ensembles and for seven common individual model experiments from CMIP3-A1B. The gold lines depict the least squares best fit line through the seven scatterplot points for the seven common individual model experiments. 
(Table 4), the tropical storm frequency change from the ZETAC regional model is $-27 \%$ for CMIP3 compared with $-23 \%$ for CMIP5-late (see also Fig. 2). The reduction is almost as large for CMIP5-early $(-20 \%)$. For hurricane (categories 1-5) frequency, the ZETAC regional model shows nominal decreases of $-17 \%(p=0.15)$ for CMIP3 and $-19 \%(p=0.08)$ for CMIP5-late, indicating marginal significance for the latter case. For U.S. landfalling tropical storms (hurricanes), the projected change is $-17 \%$ $(-23 \%)$ for CMIP3 and $+3 \%(-12 \%)$ for CMIP5-late, but none of these changes are statistically significant. For the PDI, the 18-model ensemble results show significant decreases of $-17 \%(p=0.04)$ for CMIP3 and $-20 \%$ ( $p=0.03$ ) for CMIP5-late, which may be relatively more significant owing to the aggregated nature of the metric.

Concerning the frequency of the more intense hurricanes, we can compare the hurricane model downscaling results for CMIP3 and CMIP5 scenarios in Table 4 and Fig. 1. The frequency changes have a tendency to shift from negative (for tropical storms) to positive (for very intense hurricanes) for the CMIP3 and CMIP5-early and CMIP5-late ensembles, although the statistical significance of the positive changes for intense hurricanes for CMIP5 is not as robust as for the CMIP3. For example, for category 4 and 5 hurricanes the frequency increase $(+87 \%)$ was significant $(p=0.01)$ for CMIP3, while for CMIP5-early and CMIP5-late the changes were still positive $(+45 \%$ and $+39 \%)$ but not quite significant at the $5 \%$ level ( $p=0.06$ and 0.11 , respectively, according to the Mann-Whitney-Wilcoxon test). Using a $t$ test (not shown in Table 4 ) results in a slightly more significant assessment of the changes ( $p=0.04$ for CMIP3, $p=0.05$ for CMIP5-early, and $p=0.08$ for CMIP5-late). In summary, the projected increases in category 4 and 5 frequency are significant for the CMIP3-A1B scenario but are only marginally significant for the CMIP5-early climate change scenario and even less significant for the CMIP5-late scenario.

For very intense hurricanes with winds of at least $65 \mathrm{~m} \mathrm{~s}^{-1}$, we find similar results to category 4 and 5, with large $(+250 \%)$ and significant $(p=0.05)$ increases for the CMIP3-A1B scenario but with only nominally positive changes in frequency for CMIP5 $(+83 \%$ for both CMIP5-early and CMIP5-late; Table 4). Neither of the CMIP5-based increases are statistically significant ( $p=$ 0.25 and 0.17 ). U.S. landfalling statistics are not presented for the stronger systems, owing to the fact that the higher (categories 4 and 5) storms are only simulated explicitly with the GFDL hurricane model. Those runs, which by design are limited to 5-day duration beginning 3 days prior to maximum intensity in the host (ZETAC) model, are not well suited for the examination of U.S. landfall frequency. In fact, landfall often did not occur within the 5-day timeframe of the storm experiment even in cases where a landfall eventually did occur in the (host) ZETAC model. For these reasons, the U.S. landfalling hurricane and tropical storm frequency changes obtained using the hurricane model downscaling framework (Table 4) should be treated with caution.

\section{b. Storm intensity changes}

\section{1) CMIP3 INTENSITY RESULTS}

The changes to hurricane characteristics with climate warming can also be examined in terms of frequency histograms of lifetime maximum wind speeds (one value per storm) as shown in Figs. 3 and 4 and Tables 4 and 5 for the CMIP3 downscaling. The ZETAC model histograms in Fig. 3 show the clear deficiency of the ZETAC model (present-day control simulation) at reproducing the observed intensity distribution (black dashed line), particularly for higher intensities; the ZETAC model also simulates too many moderate intensity storms. These shortcomings have largely motivated our use of the GFDL hurricane model for this study. The higher-resolution hurricane model simulates a more realistic distribution of storm intensities than ZETAC, particularly above $50 \mathrm{~m} \mathrm{~s}^{-1}$ (Fig. 4), although it remains deficient at simulating the observed frequency of the highest-intensity storms (Table 4).

There is considerable spread in the climate change experiment results among the different individual CMIP3 models as shown in Figs. 3 and 4, yet it is possible to see the common tendency of fewer storms overall in the warm-climate runs than in the control runs for both the ZETAC and GFDL hurricane models. While this reduction holds at most intensities, the tendency reverses to one of greater occurrence of storms at the highintensity end in the warmer climate-at least for most of the individual models. This amounts to a change in the shape of the normalized histogram, particularly evident for the GFDL hurricane model (Fig. 4), such that the normalized distribution becomes slightly flatter and more spread out. The consistency of the response of the higherintensity storms is easier to discern in Fig. 1, which focused on the frequency of particular categories of storms, thus allowing for a particular focus on the higher-intensity storms. Such intense storms are relatively rare in observations compared to the typical hurricanes and so they tend to be deemphasized in intensity histograms that depict the entire intensity distribution (e.g., Figs. 3, 4). They nonetheless have important implications for hurricane damage potential. For example, Pielke et al. (2008) conclude that category 4 and 5 hurricanes were responsible for nearly half of the historical U.S. hurricane damage, even though they account for only about $15 \%$ of U.S. landfalling tropical cyclones. 

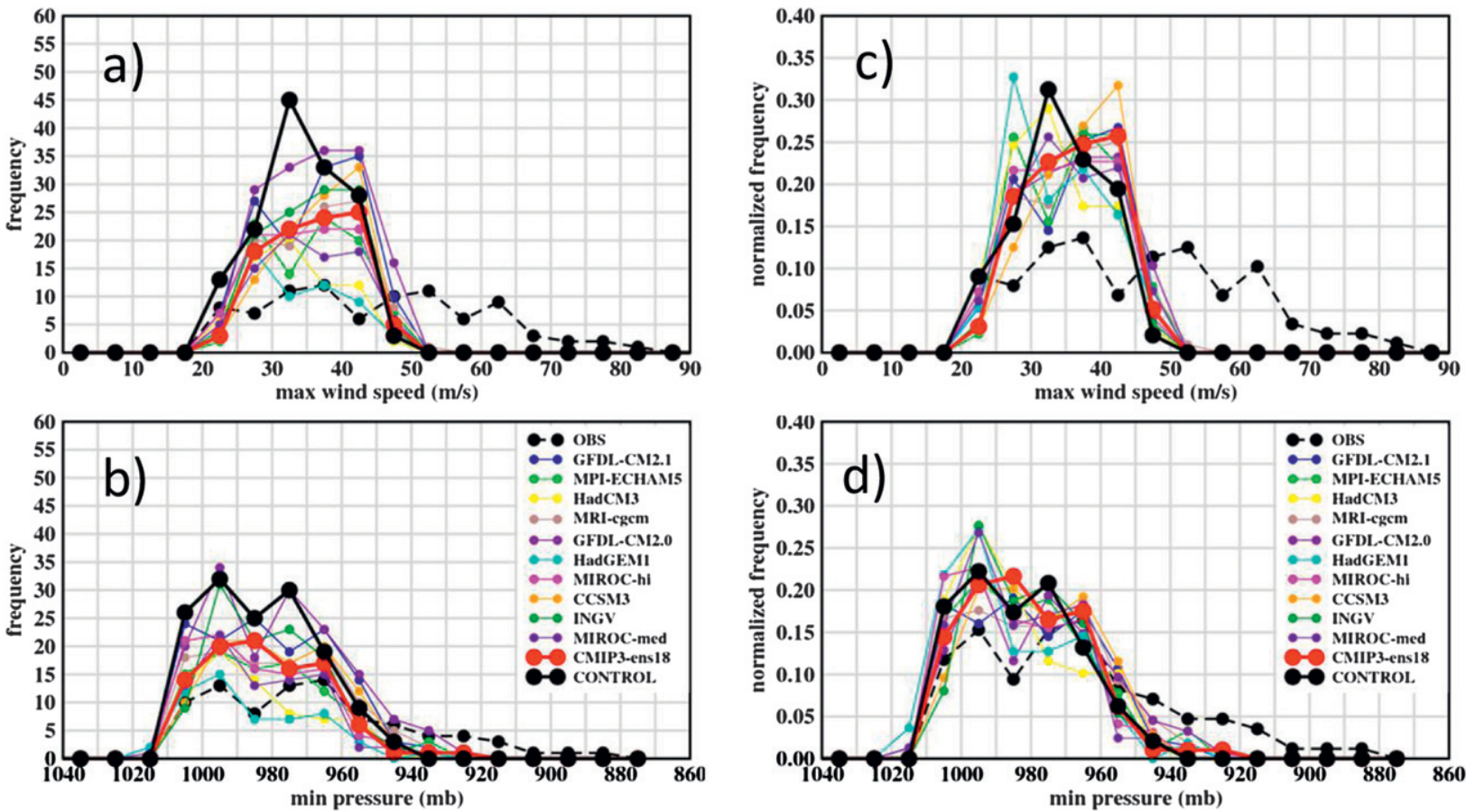

FIG. 3. Frequency histograms for North Atlantic tropical storms: (left) unnormalized and (right) normalized where the sum of the plotted histogram values equals 1 for each curve. (a),(c) Lifetime maximum surface wind speeds $\left(\mathrm{m} \mathrm{s}^{-1}\right)$ and (b),(d) minimum surface pressures (hPa) for observations (black dashed line), control run (thick black), CMIP3-A1B multimodel ensemble (CMIP3-ens18; thick red), and 10 CMIP3-A1B individual models (see legend). All results are for the ZETAC 18-km grid regional downscaling model (odd years only).

\section{2) CMIP5 VERSUS CMIP3 INTENSITY RESULTS}

The ensemble intensity distributions for CMIP3 and CMIP5 from the GFDL hurricane model, shown in Fig. 5, depict a flattening and spreading out of the intensity distribution, along with an overall reduction in frequency. That is, the high-intensity end of the intensity distribution evolves differently from the middle of the distribution, as is seen by the increase in frequency of strong storms despite the reduction in the frequency of storms in the middle of the distribution. This feature is present for both CMIP3 and CMIP5 (early- and-late twenty-first century), although it is less apparent for the CMIP5 due to the smaller (only marginally significant) change projected for the frequency of the strongest hurricanes (Table 4).

An alternate way of assessing intensity changes is to examine the average of the lifetime maximum intensities for all storms above certain threshold intensities. Table 4 shows that for the hurricane model, the average maximum wind intensity for hurricanes (winds greater than $33 \mathrm{~m} \mathrm{~s}^{-1}$ ) increases by about $4 \%-6 \%$ for the CMIP3 and CMIP5 (early- and late-twenty-first century) ensembles and that these changes are statistically significant. Table 5 shows that the range among individual CMIP3 models for this metric is $-3 \%$ to $+12 \%$, with 9 of the 10 models showing at least a nominal increase. For all tropical storms and hurricanes combined, the model ensemble changes are smaller $(0.7 \%$ to $3.4 \%)$ and only significant for CMIP5-early (Table 4). Nonetheless, the mean change in hurricane intensity is very likely more relevant for assessing hurricane damage potential. The changes in mean lifetime maximum intensity for tropical storms or hurricanes in the ZETAC regional model are generally smaller than for the hurricane model $(-0.7 \%$ to $+3.5 \%$ ), but the ZETAC model has pronounced deficiencies at simulating the intensity distribution and so is considered less suitable for examining this metric, compared to the hurricane model. To attempt to address the low bias of the intensity simulation with the ZETAC model, that model's results can be statistically refined (following Zhao and Held 2010) to explore the behavior of higher-intensity storms, at least statistically. Figure 6 shows a scatterplot of hurricane intensity change results obtained using statistical refinement versus that using dynamical downscaling. Both approaches show a preponderance of positive changes; although as can been seen in Table 4, the changes obtained using statistical refinement for the multimodel ensemble-mean CMIP3 and CMIP5 climate change scenarios tend to be smaller and/or less statistically significant than those from the dynamical downscaling (hurricane model) approach. 

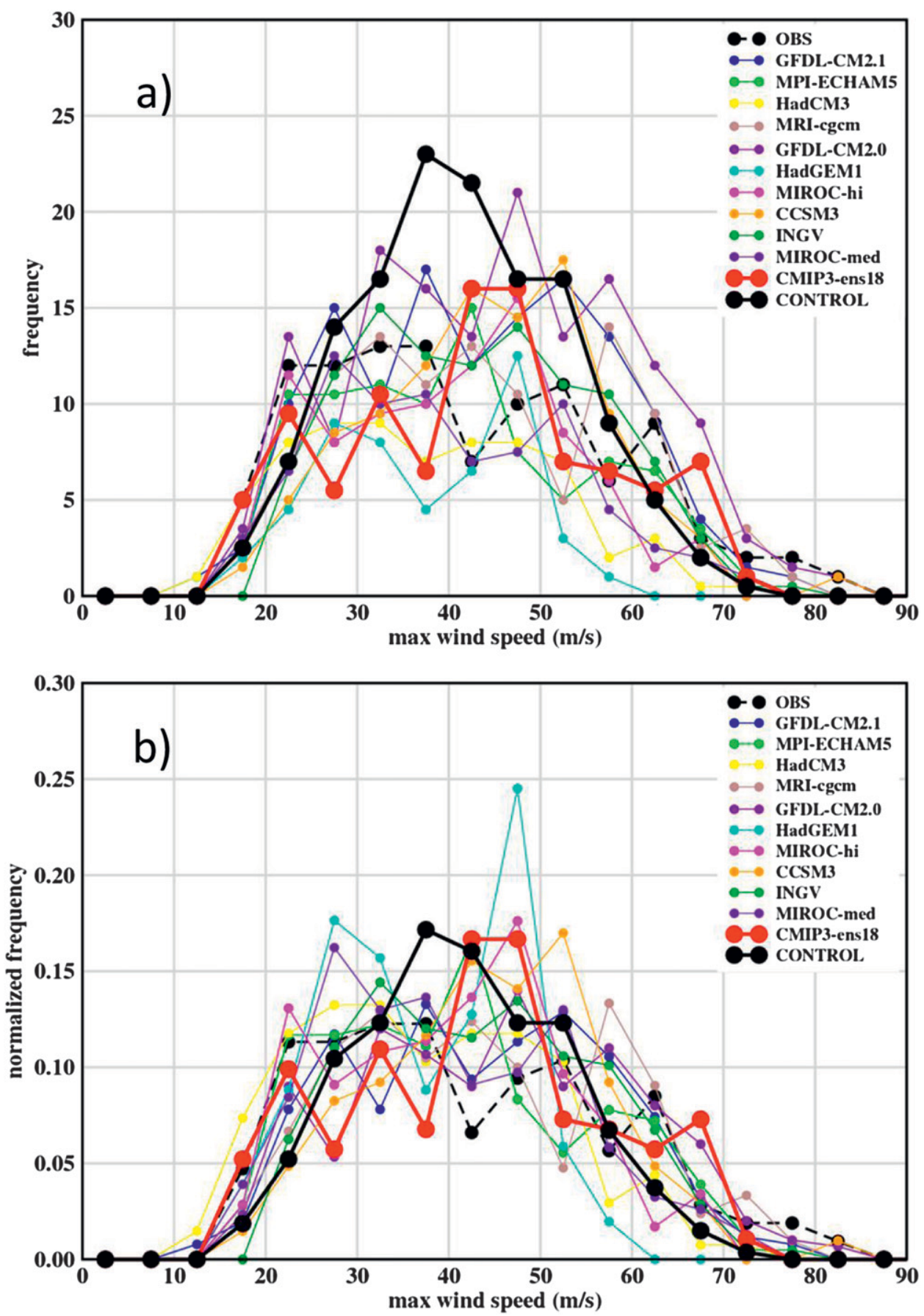

FIG. 4. As in Fig. 3, but for lifetime maximum surface wind speeds from the GFDL hurricane model downscaling experiments (ensemble of GFDL and GFDN versions): (top) unnormalized and (bottom) normalized histograms. Results shown for observations (black dashed line), control run (thick black line), CMIP3-A1B 18-model ensemble (CMIP3-ens18; thick red), and the 10 CMIP3-A1B individual models (see legend).

For the individual CMIP3 models, the intensity changes tend to be slightly larger for the statistical refinement approach, as most of the individual model symbols in Fig. 6 lie above the diagonal line.
In summary, for the CMIP3 and CMIP5 ensemblemean climate changes, the projected changes of mean intensities have a clear positive tendency, especially for hurricanes in the higher-resolution model downscaling 

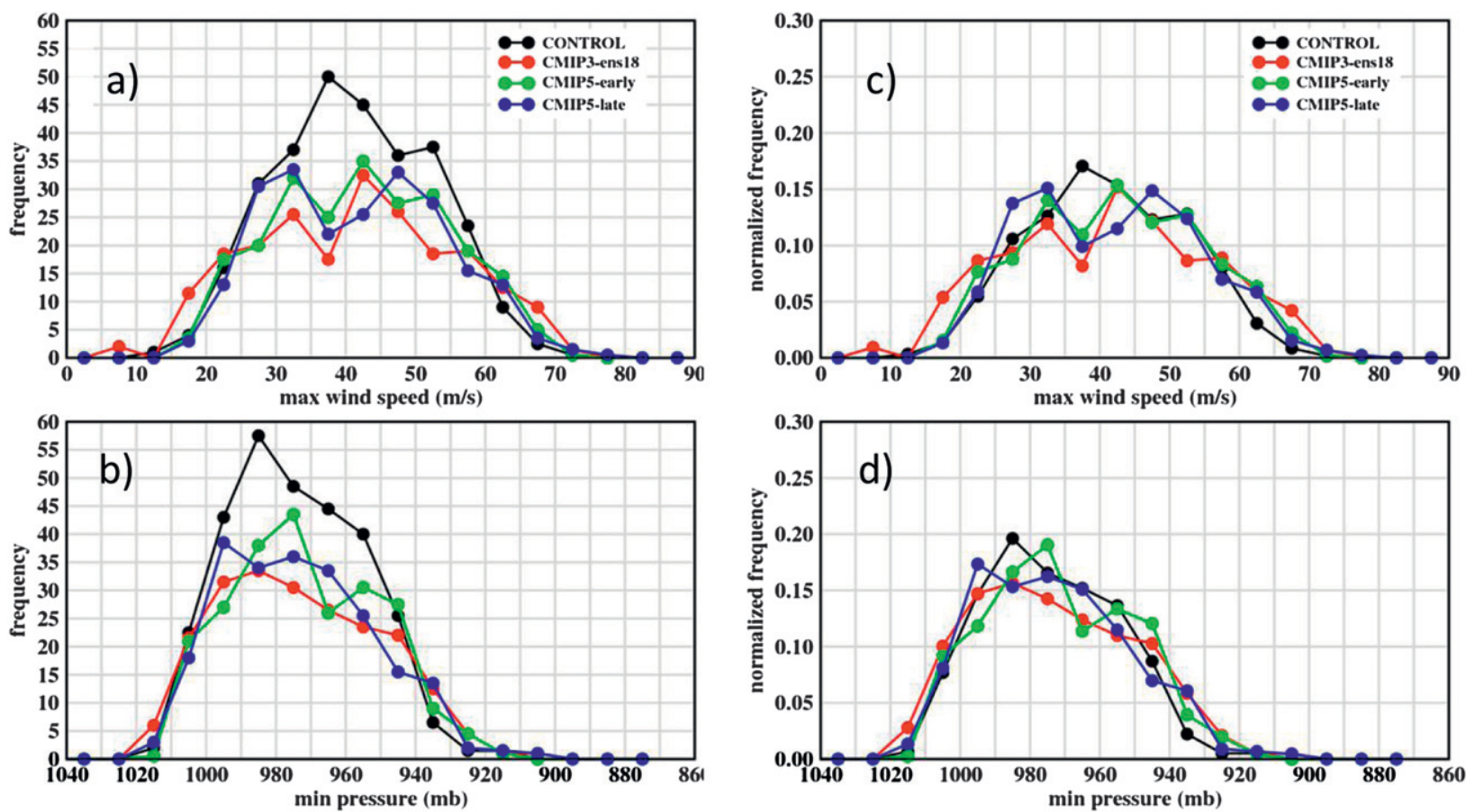

FIG. 5. As in Fig. 4, but for GFDL hurricane model downscaling experiments based on the CMIP3-A1B and CMIP5-RCP4.5 ensemblemean climate changes with (left) unnormalized and (right) normalized histograms. The ensemble of the GFDL and GFDN hurricane model versions are shown, using all 27 years (1980-2006) for the control and perturbed climate samples. Results are shown for the control run (black), CMIP3-A1B 18-model ensemble (CMIP3-ens18; red), CMIP5-RCP4.5 early-twenty-first-century ensemble (CMIP5_early; green), and CMIP5-RCP4.5 late-twenty-first-century ensemble (CMIP5-late; blue).

experiments. The results for the individual models (Table 5) have a clear tendency for increases but also have a much wider range among the experiments. For the high-resolution (hurricane model) runs, only one individual model (HadGEM1) shows a negative change of hurricane intensity; none of the models show a nominally negative change for the ZETAC runs. Considering all tropical cyclones (Maxwnd_ts), rather than just hurricanes, several individual models show negative intensity changes in the high-resolution runs, and two individual models do so in the ZETAC experiments.

\section{c. Storm-track and occurrence changes}

We present here a brief analysis of changes in the geographical distribution of storm tracks. We focus on the category 4 and 5 results for the CMIP3 and CMIP5 ensemble climate change experiments using the GFDL hurricane model. Tracks for the GFDL hurricane model for category 4 and 5 storms obtained from the GFDL/ NWS version are shown in the left column of Fig. 7, while those for the GFDN version are shown in the right column; results are compared from the CMIP3 and CMIP5 (early- and late-twenty-first century) ensemble runs. As noted earlier (Table 4), the increase in frequency of category 4 and 5 storms is statistically significant
( $p=0.01)$ for the CMIP3 ensemble but only marginally significant for the CMIP5 ensembles, especially for the late-twenty-first-century CMIP5. Nonetheless, it is of interest to compare the track maps for the category 4 and 5 storms for the various scenarios. The comparison of the geographical distribution of storm occurrence is examined in Fig. 8. The occurrence of category 4 and 5 storms shows more of a tendency for a shift toward the Gulf of Mexico and Florida region for the CMIP5 climate change runs than for the CMIP3 climate change runs. In the CMIP 3 runs, the increase of category 4 and 5 storms was more focused over the western Atlantic (i.e., centered farther from a number of U.S. landfalling regions).

In any case, these differences in regional detail between the CMIP3- and CMIP5-based intense hurricane track projections should be viewed with a caution against overinterpretation of such regional-scale details, despite the strong interest regarding the climate impacts at these scales. For example, we have not yet demonstrated that our model is capable of providing useful climate variability or change information, based on past storm data, at these smaller spatial scales (in contrast to the basinwide statistics). In addition, our hurricane model experiments are a maximum of 5-day duration and are of limited utility for examining U.S. landfalling storm behavior. 




FIG. 6. Scatterplot of projected changes (\%) in the mean lifetime maximum intensities of all hurricanes for the GFDL and GFDN hurricane model ensemble (horizontal axis) vs the statistically adjusted intensities from the ZETAC regional model (vertical axis). See legend for identification of experiments.

We are planning to address this limitation in future studies.

The reduction in tropical storm frequency coupled with a tendency for an increase of intense storm occurrence (Figs. 7, 8; Table 4) can be further explored in terms of large-scale environmental changes simulated by the CMIP3 and CMIP5 models for the SRES A1B (CMIP3) and RCP4.5 (CMIP5) scenarios. Figure 9 shows maps of the projected changes in tropical cyclone potential intensity (PI), vertical wind shear, SST, and local SST relative to the tropical mean SST, as discussed in Vecchi and Soden (2007a). Also shown for comparison are results from $2 \times \mathrm{CO}_{2}$ transient experiments with the CMIP3 and CMIP5 models (which are based on linear trends from years $1-70$ of $+1 \% \mathrm{yr}^{-1} \mathrm{CO}_{2}$ experiments obtained from the CMIP3 and CMIP5 model archives). Each of the CMIP3 and CMIP5 multimodel twenty-first-century scenarios shows a band of minimum (or even negative) PI change across the Atlantic basin. While some areas of PI decrease are simulated, the PI changes are predominantly positive over the basin's main tropical cyclone regions as a whole. The regions of projected PI decrease are smaller and less pronounced in the CMIP5-RCP4.5 runs than in the CMIP3 or $2 \times \mathrm{CO}_{2}$ runs. Similarly, the CMIP3-A1B and the $2 \times \mathrm{CO}_{2}$ runs (for both CMIP3 and CMIP5) show large regions of negative relative SST across the Atlantic, in contrast to the CMIP5-RCP4.5 ensembles. These regions of negative relative SST correspond roughly to regions with enhanced vertical wind shear. Since a decrease in tropical storm frequency was found for the CMIP5-RCP4.5 as well as CMIP3-A1B downscaling, we speculate that the change in the wind shear of the mean circulation is not the primary driver of the decrease in Atlantic tropical storm frequency seen across our experiments. Moreover, the $\mathrm{CO}_{2}$-only experiments, which show the increased shear and decreased relative SST for both CMIP3 and CMIP5, indicate that the absence of these features in the CMIP5-RCP4.5 ensemble is apparently related to changes in nongreenhouse radiative forcing (RCP4.5 versus SRES A1B) as opposed to changes in the models' responses to increasing greenhouse gases (cf. the similarity of CMIP5 and CMIP3 $\mathrm{CO}_{2}$-only responses). The preponderance of positive potential intensity changes of a few meters per second in the CMIP3-A1B and CMIP5-RCP4.5 scenarios is broadly consistent with the simulated increase in lifetime maximum intensities of hurricanes in our hurricane model downscaling and with the increase in frequency of very intense (categories 4 and 5) hurricanes.

The CMIP3 and CMIP5 (early- and late-twenty-first century) model projections generally indicate an amplified 


\section{Category 4 \& 5 Hurricane Tracks (27 years) \\ GFDL Hurricane Model \\ CONTROL - 14 storms \\ GFDN Hurricane Model \\ CONTROL - 17 storms}



CMIP3_ens18 - 28 storms

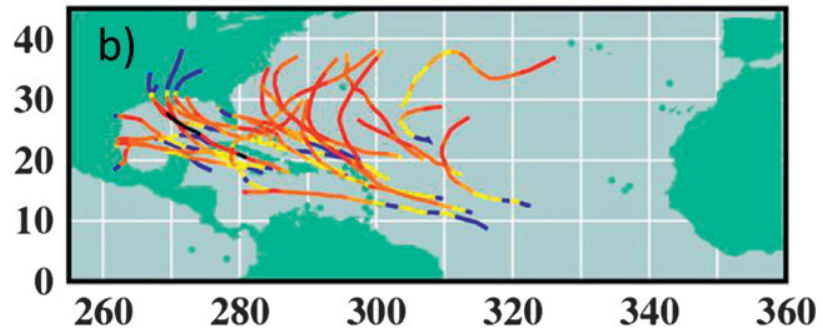

CMIP5_EARLY - 20 storms

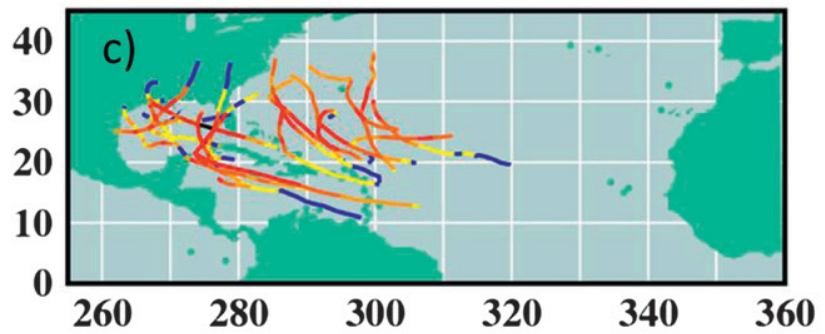

CMIP5_LATE - 19 storms



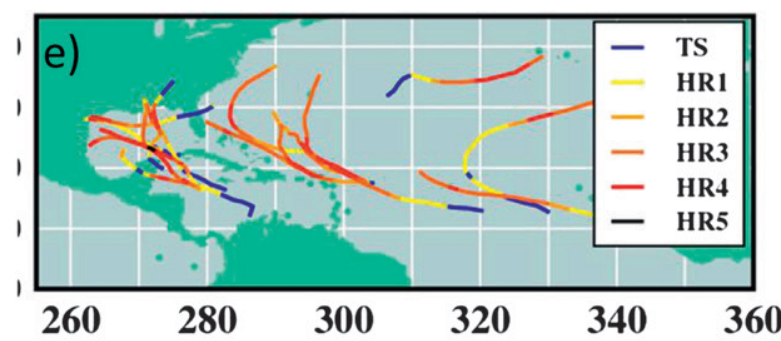

CMIP3_ens18 - 30 storms

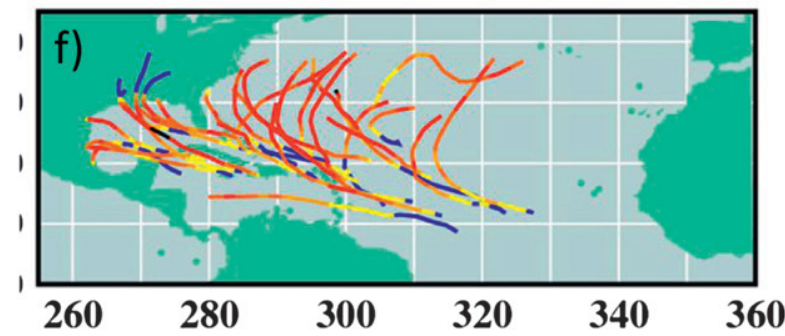

CMIP5_EARLY - 25 storms

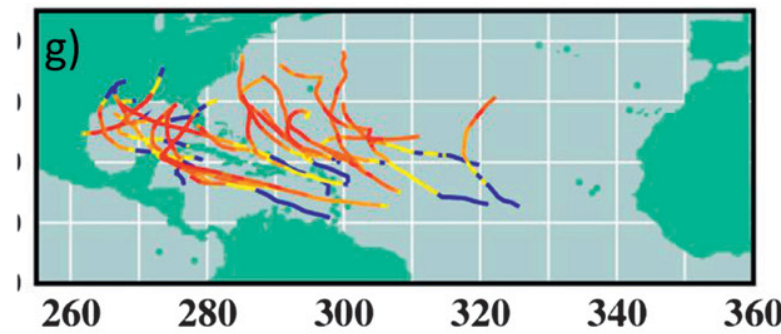

CMIP5_LATE - 24 storms

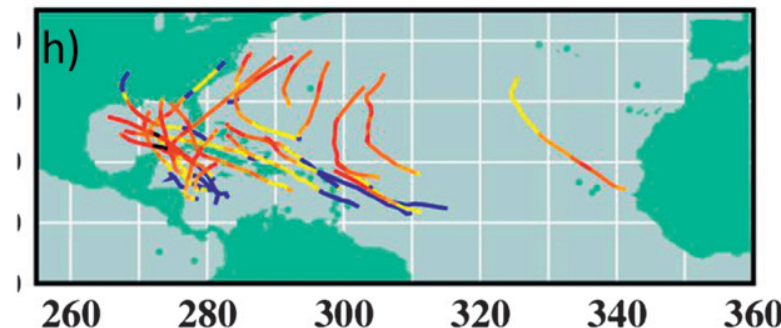

FIG. 7. Tracks and intensities of all storms reaching category 4 or 5 intensity $\left(\geq 59 \mathrm{~m} \mathrm{~s}^{-1}\right)$ in the GFDL hurricane model downscaling experiments (27 seasons), using model versions (left) GFDL or (right) GFDN. Results shown for the (a),(e) control climate; (b),(f) CMIP3-A1B 18-model late-twenty-first-century ensemble climate change; (c),(g) CMIP5-RCP4.5 early-twenty-first-century ensemble; and (d),(h) CMIP5-RCP4.5 late-twenty-first-century ensemble. 


\section{Cat 4 \& 5 Hurricanes: GFDL + GFDN Hurricane Model Ensemble CONTROL}

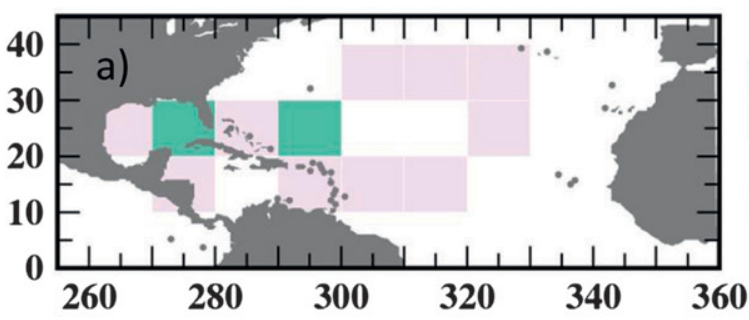

CMIP3_ens18

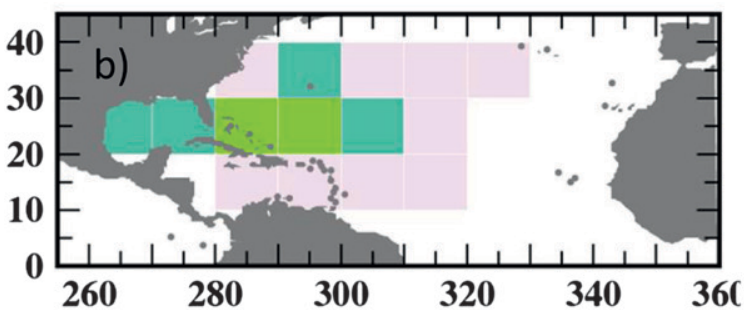

CMIP5_EARLY

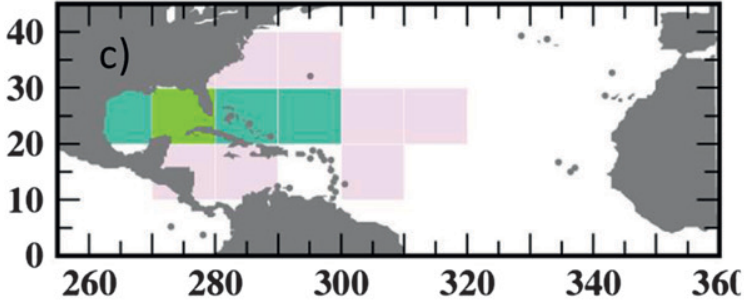

CMIP5_LATE

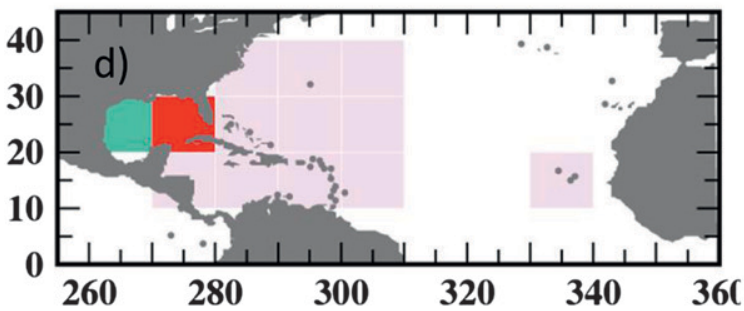

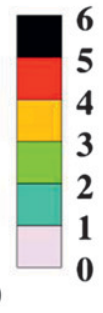

Differences

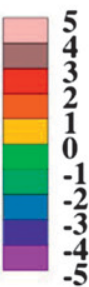

CMIP3_ens18 minus CONTROL

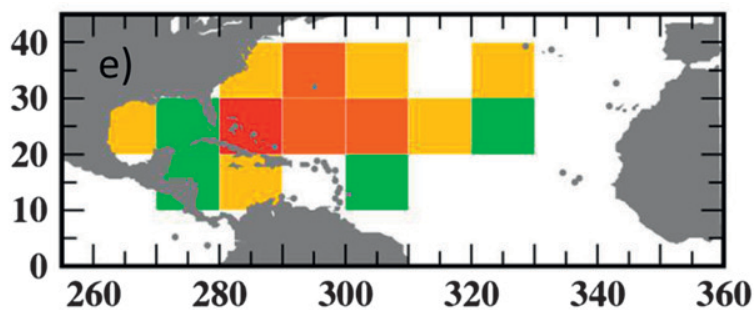

CMIP5_EARLY minus CONTROL

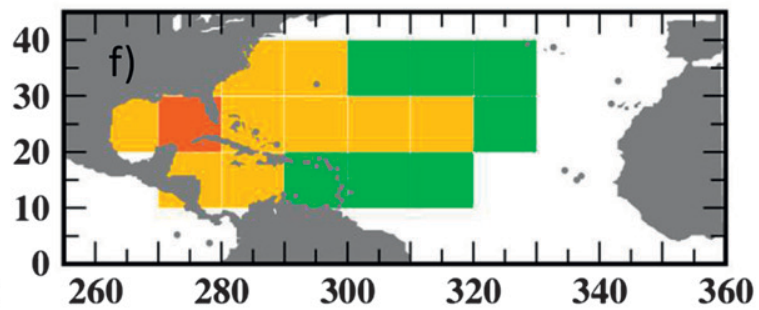

CMIP5_LATE minus CONTROL

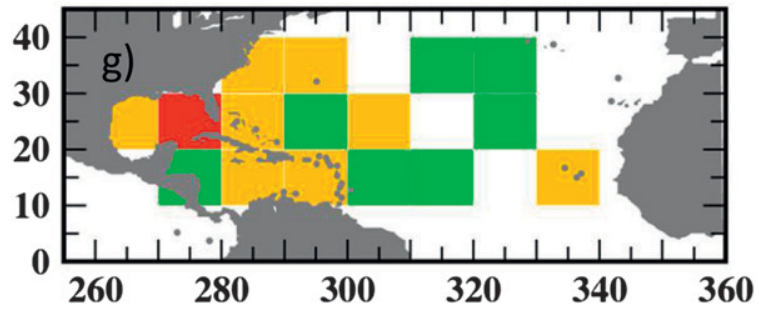

FIG. 8. Geographical distribution of the (left) projected rate of occurrence or (right) change in rate of occurrence of category 4 and 5 storms for (a) control; (b),(e) CMIP3-A1B late-twenty-first-century ensemble; (c),(f) CMIP5-RCP4.5 early-twenty-first-century ensemble; and (d),(g) CMIP5-RCP4.5 late-twenty-first-century ensemble. The combined results obtained using the GFDL and GFDN versions of the GFDL hurricane model (scaled as storm occurrences per decade in $10^{\circ} \times 10^{\circ}$ grid boxes) are shown.

warming response in the upper troposphere compared to the surface [not shown, but see Knutson and Tuleya (2004) or Hill and Lackmann (2011)]. For example, the mean warming at $300 \mathrm{hPa}$ is about 2.2 times larger than near the surface for the main development region (MDR; $10^{\circ}-20^{\circ} \mathrm{N}, 80^{\circ}-20^{\circ} \mathrm{W}$ ) for both the CMIP3 and the CMIP5 ensembles; for 9 of the 10 individual CMIP3 models, the warming ranges from about 1.9 to 2.7 times larger than near the surface (with HadGEM1 being an outlier with a factor of 3.5). These changes are thus broadly similar to those reported in the previous studies. The enhanced warming with height in the climate model projections likely limits the hurricane intensity increase in response to climate warming as simulated in the hurricane model (e.g., Shen et al. 2000; Knutson and Tuleya 2004; Emanuel et al. 2013; Vecchi et al. 2013a), 

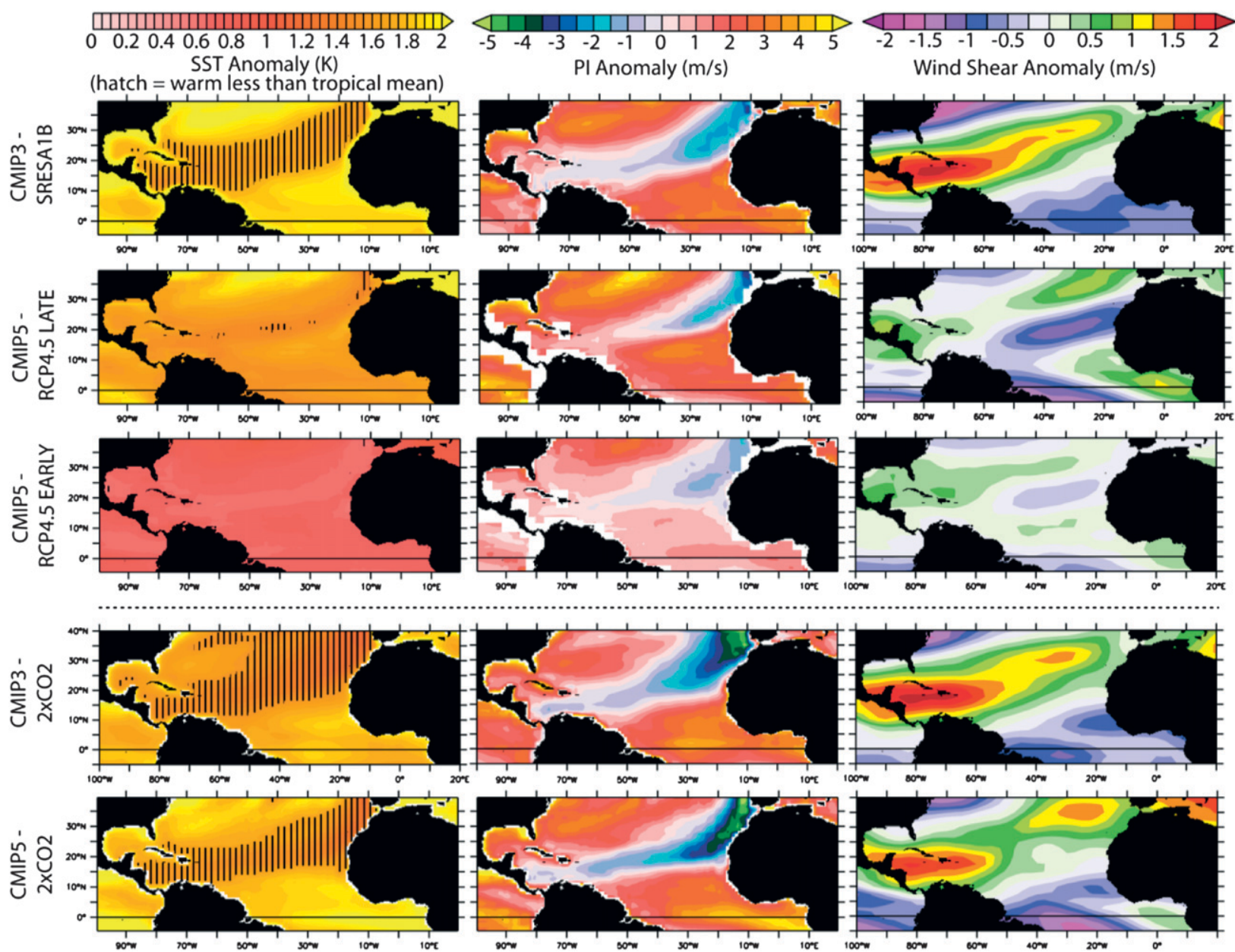

FIG. 9. Changes (warm climate - control; August-October season) in large-scale environmental fields from the (row one) original CMIP3 and (rows two and three) CMIP5 climate model experiments and time periods (see text). (left) SST change (color shading) and the relative SST change field computed as local SST change minus the tropical mean $\left(30^{\circ} \mathrm{N}-30^{\circ} \mathrm{S}\right)$ SST change (K, contours with hatching indicating where the SST warming $<$ the tropical mean SST warming). (middle) Tropical cyclone PI change ( $\left.\mathrm{m} \mathrm{s}^{-1}\right)$. (right) Difference in vertical wind shear vector $\left(200 \mathrm{hPa}-850 \mathrm{hPa} ; \mathrm{m} \mathrm{s}^{-1}\right)$ magnitude between the warm climate and control. (bottom two rows) CMIP3-2 $\times \mathrm{CO}_{2}$ and CMIP5-2 $\times \mathrm{CO}_{2}$ changes were computed from linear trends over years $1-70 \mathrm{of}^{+} 1 \% \mathrm{yr}^{-1} \mathrm{CO}_{2}$ experiments using data from the CMIP3 and CMIP5 model archives. Further details of computation methods for SST, PI, and wind shear are given in Vecchi and Soden (2007b).

compared to what it would be for a hypothetical uniform warming with height, for example.

We have computed storm propagation speed statistics from our storm samples (labeled trans speed in Tables 3 and 4). The results for the CMIP3 and CMIP5 ensembles indicate no significant changes, and only 2 of the 10 individual CMIP3 model projections show a significant change (increase). In short, there is not a clear consistent signal in the storm propagation speed projections.

\section{d. Storm-related precipitation rate changes}

A robust feature in our model projections is an increase of precipitation rates averaged within the near-storm region. Figures 10a,b summarizes the statistical analysis for the average precipitation rate within $100 \mathrm{~km}$ of the storm center for all tropical storms and hurricanes combined in the ZETAC (Fig. 10a) and hurricane model (Fig. 10b) experiments, including results for the individual CMIP3 model experiments. This metric includes the entire storm lifetime (or up to 5 days in the case of the hurricane model runs), which is dominated by the time spent over the open ocean. Thus, the precipitation results shown here primarily represent hurricane-related rainfall over the ocean, as opposed to landfalling or inland storms. For the ZETAC model, the average change for the CMIP3 18-model ensemble is $+19 \%$, while for the CMIP5-early and CMIP5-late ensembles the average change is $+8 \%$ and $+13 \%$, respectively (Table 4 ), 
a)

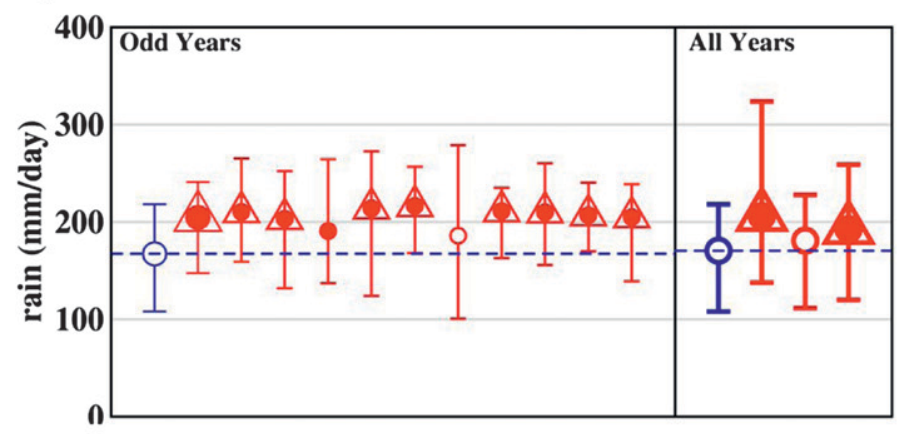

b)

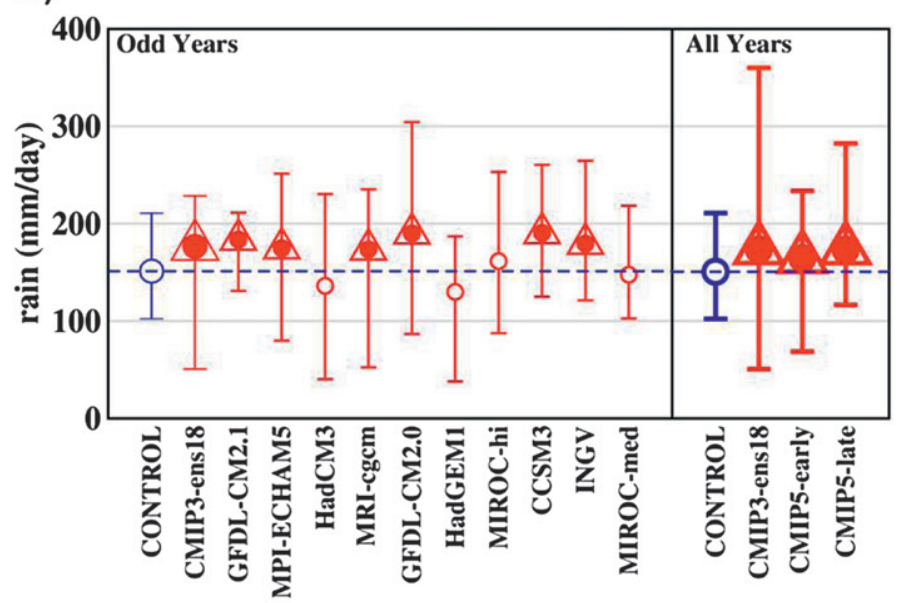

c)

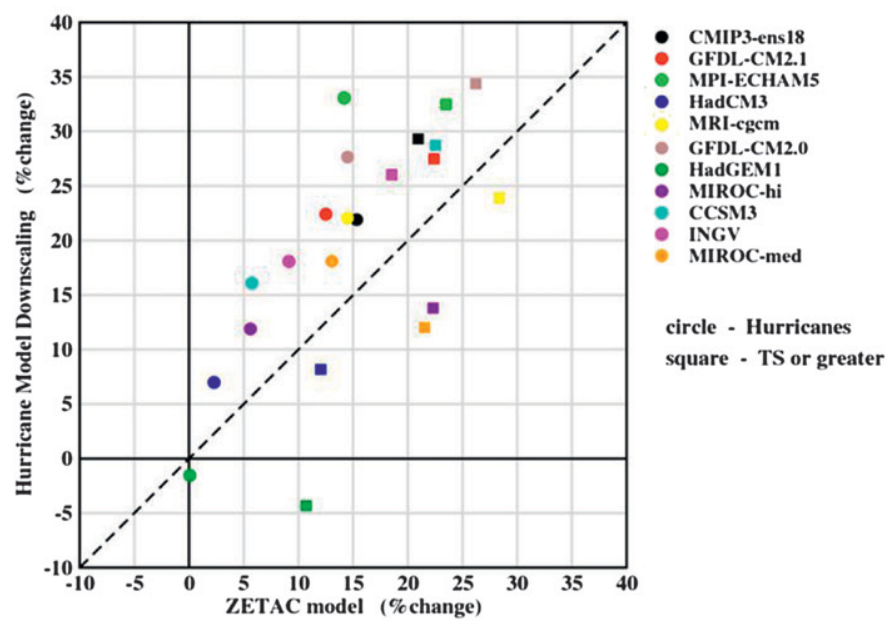

FIG. 10. As in Fig. 1, but for rain rate averaged within $100 \mathrm{~km}$ of the storm center and averaged over all tropical storm and hurricane periods $\left(\mathrm{mm} \mathrm{day}^{-1}\right)$ for the (a) ZETAC regional model or the (b) GFDL-GFDN hurricane model ensemble. (c) Scatterplot hurricane model vs ZETAC model of changes (\%) between the control and warm climate in hurricane (circles) or tropical storm/ hurricane (squares) rainfall rate averaged within $100 \mathrm{~km}$ of the storm center for the CMIP3-A1B late-twenty-first-century ensemble (black) and individual CMIP3 models. The dashed line illustrates a 1:1 relation between the results from the two modeling frameworks. 


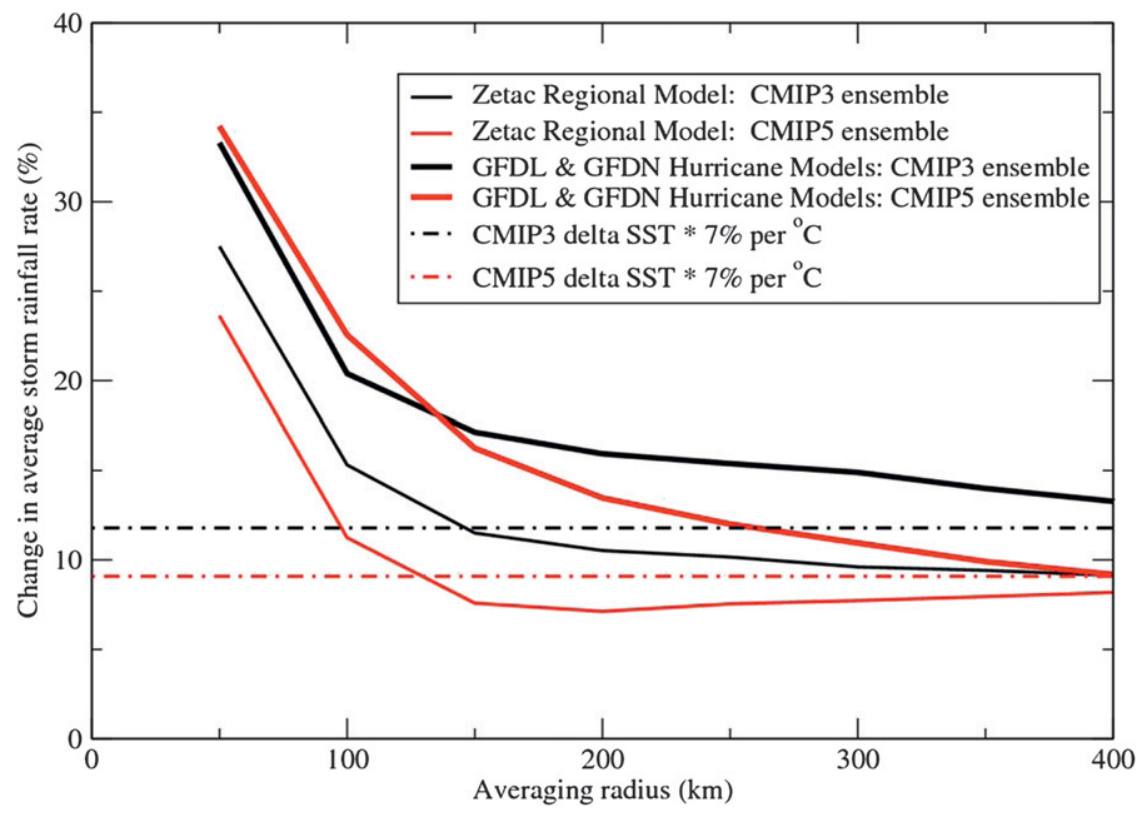

FIG. 11. Change (\%) between the control and warm climate in average hurricane rainfall rate for various averaging radii about the storm center $(\mathrm{km})$ for the CMIP3-A1B (black) and CMIP5-RCP4.5 (red) late-twenty-first-century multimodel ensemble climate changes based on the ZETAC regional model (thin solid lines) or the GFDL-GFDN hurricane model ensemble (thick solid lines). The dashed lines illustrate idealized water vapor content scaling, obtained by multiplying the average SST change in the region $10^{\circ}-25^{\circ} \mathrm{N}, 20^{\circ}-80^{\circ} \mathrm{W}$ by $7 \%{ }^{\circ} \mathrm{C}^{-1}$.

with all changes being statistically significant. In the hurricane model (Fig. 10b; Table 4), the changes are even larger, with an increase of $+22 \%$ for the CMIP3 ensemble, $+18 \%$ for CMIP5-early, and $+19 \%$ for CMIP5late. For the 10 individual CMIP3 models that we have examined, Table 5 shows that in the ZETAC model runs, all 10 runs have a positive change in this metric, ranging from $+11 \%$ to $+28 \%$, with 9 out of 10 having statistically significant increases $(p<0.05)$ according to the MannWhitney-Wilcoxon test. For the hurricane model downscaling runs, 7 of the 10 individual models have significant increases in the $100-\mathrm{km}$-averaged precipitation rate. Tables 4 and 5 show that the precipitation rate projections for hurricanes are similar to those for all tropical storms and hurricanes combined; however, they are less robust statistically, especially in the ZETAC model runs. For example, only 5 of the 10 individual models show a significant increase in this metric for ZETAC, while 7 of the 10 have a significant increase in the hurricane model runs. The changes for the CMIP5-early ensemble are consistently much smaller than for the CMIP5-late ensemble for the ZETAC model, but this distinction is not as evident for the hurricane model runs. The results hint that the precipitation rate changes (Fig. 10; Table 4) are more closely tied to absolute temperature changes than hurricane frequency changes are. The precipitation rate results show a consistent positive tendency across a number of model projections for both downscaling models, whereas the hurricane frequency changes tend to be negative for hurricanes up to category 3 but positive for categories 4 and 5. Previous studies that have explored this metric have generally found that an increase in tropical cyclone precipitation rates is a relatively robust climate change response (see review in Knutson et al. 2010).

Figure 10c shows a model-by-model scatterplot comparison of precipitation rate change results for the ZETAC versus hurricane model downscaling runs. The comparison shows a relatively good agreement between the two downscaling methods in their projections of changes in precipitation rate, although the hurricane model tends to project a larger percentage increase in future precipitation rate than does the (lower resolution) ZETAC model.

Figure 11 shows the hurricane precipitation rate changes for CMIP3 and CMIP5-late ensembles, for both the ZETAC and hurricane models, as a function of averaging the radius about the storm center, varying from 50 to $400 \mathrm{~km}$. For all sets of experiments, the percentage increase is amplified nearer to the storm but then tends to asymptote at roughly $+10 \%$ at larger radii $[\sim(200$ 400) $\mathrm{km}]$. We can use a simple moisture scaling argument to interpret the asymptotic behavior at larger radii. If we assume that the moisture budget within the broad 
near-storm environment (within $400 \mathrm{~km}$ of the center) is dominated by moisture convergence from the larger environment, then fractional increases in the atmospheric moisture content in the warmer atmosphere should lead to similar fractional increases in the moisture convergence and thus in precipitation rate. A representative SST change for our experiments (August-October mean, averaged $10-25^{\circ} \mathrm{N}, 20-80^{\circ} \mathrm{W}$ ) is $1.7^{\circ} \mathrm{C}$ for $\mathrm{CMIP} 3$ and $1.3^{\circ} \mathrm{C}$ for CMIP5-late. Assuming a $7 \%$ increase in lowertropospheric atmospheric water vapor content per degree Celsius SST change, we obtain the $\sim 10 \%$ increases depicted by the dashed lines in Fig. 11 for the CMIP3 and CMIP5 environments. Thus, our results show that this scaling argument describes our model precipitation increases fairly well for averaging radii of $200-400 \mathrm{~km}$. However, the more amplified model precipitation response at smaller radii (between 50 and $150 \mathrm{~km}$ ) does not agree with this simple scaling. The amplification of the fractional increase near the storm center is most pronounced in the higher-resolution hurricane model runs, where increases of the order of $20 \%$ and $33 \%$ occur at averaging radii of 100 and $50 \mathrm{~km}$. For the ZETAC model, the increases are of the order of $15 \%(25 \%)$ for radii of 100 (50) $\mathrm{km}$. These results suggest that other processes, such as the intensification of the hurricane circulation, may play a more important role in the response of the hurricane inner-core precipitation rates to climate warming.

\section{Discussion and conclusions}

In this study, we have conducted a large number of numerical experiments to explore the dependence of Atlantic hurricane activity on projected climate changes as obtained from the CMIP3 and CMIP5 coupled model data archive. We have compared downscaling results for CMIP3 against CMIP5-early and CMIP5-late twentyfirst-century projections and examined the spread of the results within a 10 -member subset of the 18 individual models used to form the CMIP3 ensemble.

We have used two different downscaling models-an $18-\mathrm{km}$ grid regional model (ZETAC) and a $50-\mathrm{km}$ grid global model (HiRAM C180) - and have simulated substantial sets (27) of 3-month seasons or years of hurricane activity in order to examine the robustness of the initial downscaling step. We focus especially on the simulated frequency of tropical storms and hurricanes, as the interannual variability of these metrics since 1980 is well produced by these models (e.g., Knutson et al. 2008; Zhao et al. 2009). A caveat to the ZETAC model results is that the overall frequency of simulated tropical storms in the model is sensitive to the nudging time scale used, as shown in Knutson et al. (2007). To study the most intense hurricanes, we have performed an additional downscaling step on the individual storms in the ZETAC model, using two versions of a $9-\mathrm{km}$ grid operational hurricane prediction model with ocean coupling (Bender et al. 2010). This hurricane model has been developed and refined for operational hurricane prediction use, and thus it can simulate more intense systems and more realistic spatial structures for hurricanes than the lower-resolution downscaling models.

Several findings with varying degrees of robustness have emerged from this study. One of the most striking features from the ZETAC regional model is its consistent projection of fewer Atlantic tropical storms in warmer climates. The ensemble model changes are $-27 \%$ (CMIP3), -20\% (CMIP5-early), and -23\% (CMIP5late) and all statistically significant. The range across individual CMIP 3 models is $-62 \%$ to $+8 \%$, with 5 of the 10 models showing a statistically significant decrease. Our results quoted above from the ZETAC regional model are overall rather similar to those from the $\mathrm{C} 180$ global model (Fig. 2). On the other hand, as shown in a recent review (Knutson et al. 2010), agreement on the sign of the projected change of Atlantic tropical storm frequency results is not as robust when one considers other published studies. Examples of studies that project at least nominally positive changes in Atlantic tropical storm frequency include Sugi et al. (2002), Oouchi et al. (2006), Chauvin et al. (2006; one of two models), Emanuel et al. (2008), Sugi et al. (2009; six of eight experiments), and Murakami et al. (2012; one of three multimodel ensemble experiments). Further insight on the differences in model projections can be gained by replotting the tropical storm frequency projections of several published studies in a scatterplot (Fig. 12) against the statistical downscaling projection of Villarini et al. (2011). The Villarini et al. (2011) projected changes are approximately proportional to the change in relative SST for the MDR. The comparison shows that dynamical models projecting increased tropical storm frequency were usually forced with (or had computed within the model) SST warming in the tropical Atlantic that exceeded the tropical mean warming. The variance explained by the statistical downscaling model is $55 \%$. Thus, the analysis helps to reconcile the differences between previously published Atlantic tropical storm projections and our current results.

A second robust result is the contrasting change in storm frequency for weak versus strong tropical cyclones. The projections typically show a reduction in the overall frequency of tropical storms and hurricanes but with an increase in the frequency of the most intense hurricanes simulated. The transition from decreasing to increasing storm frequency, as one moves to higher intensity classes, is one of the most robust intensity-related features in our hurricane model simulations. This transition is seen most 




FIG. 12. Comparison of published dynamical model projections of Atlantic basin tropical storm frequency changes vs the statistical downscaling model of Villarini et al. (2011), which is based on relative SST changes. The figure shows that in most cases where the dynamical models projected increased tropical storm frequency, those models were usually being forced with or had internally computed SST warming of the tropical Atlantic that exceeded the tropical mean. The blue stars depict the CMIP3, CMIP5-early, and CMIP5-late multimodel ensemble results from the ZETAC model.

clearly in the figures examining changes in the frequency of different categories of storms (Fig. 1) but is also apparent in the histograms of storm intensities for the hurricane model (Figs. 4, 5). The feature is more pronounced in the hurricane model than in the ZETAC regional model (Fig. 1). We have emphasized the hurricane model results in our assessment of strong intensities because that model has a much more realistic simulation of intense hurricanes than the ZETAC regional model. The projected increase in category 4 and 5 hurricane frequencies in the hurricane model $(+87 \%)$ is statistically significant in our experiments for the CMIP3 18-model ensemble climate change and for 3 of the 10 individual CMIP3 models (Fig. 1; Table 5). This feature is also present in the CMIP5 (early- and late-twenty-first century) downscalings, although there the change is smaller in magnitude ( $+45 \%$ and $+39 \%$, respectively) and only marginally significant, particularly for the CMIP5-late ensemble. A less robust change in intense storm frequencies is derived by using a statistical refinement of the ZETAC intensities (Table 4), as opposed to dynamical downscaling using the hurricane model.

The related increase in mean lifetime maximum storm intensity is apparent in the simulations-particularly in the (higher resolution) hurricane model downscaling runs shown in Table 4-and is more pronounced for storms of at least hurricane intensity than for all tropical cyclones with winds exceeding $17 \mathrm{~m} \mathrm{~s}^{-1}$. In Knutson et al. (2010), the globally averaged mean intensity of tropical cyclones was assessed as likely to increase with climate warming, although they noted that the uncertainties of such projections were larger for individual basins. In their Table S2 (intensity projections), the published intensity projections for the Atlantic basin showed relatively small changes in 
some studies and ranged even to negative values for some individual models that were analyzed (e.g., Vecchi and Soden 2007b). In a recent idealized study with regional models of 6- and 2-km grid spacing, Hill and Lackmann (2011) report an intensity increase of $9 \%-14 \%$ for the latetwenty-first-century Atlantic conditions in terms of central pressure deficit. Dividing by two for a rough comparison with our wind speed results, Hill and Lackmann's projections would be a $4.5 \%$ and $7 \%$ increase for the 6 - and 2-km model. Our current results for hurricane intensities (a statistically significant $+4 \%$ to $+6 \%$ increase for the CMIP3 and CMIP5-early and CMIP5-late multimodel ensemble conditions, with a range of $-3 \%$ to $+11 \%$ for individual CMIP3 models) are generally consistent with these earlier findings. Individual model downscaling for this metric tend to show a larger range than the multimodel ensemble downscalings (and are based on a smaller sample of years in our study), although even those results show a clear preference for an increase.

While very intense hurricanes are relatively rare, their importance is considerable. For example, Mendelsohn et al. (2012) note, "With the present climate, almost 93\% of tropical cyclone damage is caused by only $10 \%$ of the storms." Of even greater relevance to our results is an analysis of U.S. hurricane damage statistics partitioned by storm category (Pielke et al. 2008). They conclude that category 4 and 5 hurricanes were responsible for nearly half of the historical U.S. hurricane damage, even though they account for only about $15 \%$ of U.S. landfalling tropical cyclones. Clearly, the strongest tropical cyclones inflict a disproportionate impact on society in terms of storm damage.

A final robust feature of our simulations is the increase in storm-related precipitation rates, which is significant in the CMIP3 and CMIP5 (early- and late-twenty-first century) ensemble projections and for most of the individual CMIP3 models examined. The fractional rate of increase is amplified for averaging radii less than about $150 \mathrm{~km}$ (Fig. 11). Our results show that the hurricane precipitation rate increases robustly in the warm-climate simulations in both the ZETAC regional model and the GFDL hurricane model. The near-storm amplification is larger in the hurricane model than in the ZETAC regional model. Increases of order $20 \%$ (33\%) occur at averaging radii of $100(50) \mathrm{km}$, respectively, for the hurricane model. At relatively larger averaging radii (roughly $200-400 \mathrm{~km}$ ), the model results appear to asymptote to change levels close to what would be expected from simple ClausiusClapeyron atmospheric water vapor scaling arguments. Our precipitation results are broadly consistent with and provide further support for results in a recent review of tropical cyclone climate change simulation studies (Knutson et al. 2010) and with the recent Atlantic hurricane downscaling study of Hill and Lackmann (2011).
A notable difference relative to our previously published work (Bender et al. 2010) is that the CMIP5/ RCP4.5 ensemble climate change projections (early- and late-twenty-first century), when downscaled, lead to only marginally significant $(+45 \%$ and $+39 \%)$ increases in the frequency of category 4 and 5 hurricanes. In contrast, the CMIP3-A1B ensemble leads to a larger $(+87 \%)$ statistically significant increase in category 4 and 5 hurricanes. Our results for high-intensity storms can also be compared with those of Murakami et al. (2012), who used a high-resolution global model but reported category 5 storm results also for the Atlantic basin for a late-twentyfirst-century CMIP3-A1B ensemble scenario (auxiliary information provided by H. Murakami 2011, personal communication). Their model projects a nonsignificant increase in category 4 and 5 storm days in the Atlantic basin $(+15 \%)$ and globally $(+4 \%)$. For category 5 storm days, their model projects significant increases $(+56 \%$ globally and $+290 \%$ in the Atlantic basin). There are several important caveats to the results from the various models. For example, the GFDL hurricane model has a substantial $(\sim 50 \%)$ low bias in its simulation of Atlantic category 4 and 5 hurricane frequency under present climate conditions (1980-2006). Murakami et al. (2012) report a relatively small bias in their present-day simulation of Atlantic category 5 storm days but a large positive bias (almost a factor of 4) in their simulation of Atlantic category 4 and 5 storm days. In addition, the global model used by Murakami et al. (2012) does not include an interactive ocean component, in contrast to the hurricane model used in the present study and Bender et al. (2010).

The underestimation of category 4 and 5 storm frequency in our hurricane model simulations compared to observations (Table 4) is a limitation of our modeling system in the context of this paper and Bender et al. (2010). However, we are not aware of any other dynamical modeling study to date that produces a more realistic simulation of Atlantic category 4 and 5 frequency, including the multidecadal variation of storm intensity (Bender et al. 2010, their Figs. 1a-d). Our judgment is that the intensity distribution in our model is realistic enough at the category 4 and 5 level that we can start to take the frequency projections of these very intense storms seriously. We have chosen to present changes in category 4 and 5 storm numbers in terms of fractional changes rather than absolute changes because of the bias in our control simulations. It is our judgment that this is an appropriate way to attempt to account for the bias at the present time. A more satisfying remedy awaits improvements in our model [e.g., increase of resolution to better resolve the storm core and eyewall region; Chen et al. (2007); Gentry and Lackmann (2010)], which we 
hope will lead to a simulated frequency of category 4 and 5 storms that is closer to the observed.

The question arises whether the projected increases in category 4 and 5 storm frequencies would be detectable in the twenty-first century if they occurred. Bender et al. (2010) estimated that the CMIP3-A1B increase of about $10 \%$ decade $^{-1}$ would require roughly 6 decades to be detectable as a linear trend. The projected change for CMIP5-early of a 45\% increase for 2016-35 compared to 1986-2005 is another possible candidate signal for detection. The difficulty is in estimating the internal variability noise in which this signal would be embedded. In an idealized assumption, we can try to estimate the noise from the examination of the category 4 and 5 observations (see supplemental material of Bender et al. 2010). If the internal variability is estimated from either the raw observations or as the residual from a linear trend through the observed data, then the projected change (45\%) would not be significant. However, if we assume that the forced signal in category 4 and 5 hurricanes is a fourth-order polynomial fit through the original observed time series and the residual from this fourth-order fit is the internal variability, then the projected CMIP5early signal would be detectable above the internal variability noise. In short, this idealized analysis suggests that whether the increase in category 4 and 5 frequency we project for the CMIP5 scenario will detectable or not depends on the estimate of internal variability noise, which remains uncertain at this time.

Considering hurricanes with winds exceeding $65 \mathrm{~m} \mathrm{~s}^{-1}$ (which occur about once per decade in the control run compared with about once every $2 \mathrm{yr}$ in the observations), the 18-model ensemble-mean CMIP3 change from the hurricane model is statistically significant $(+250 \%)$, compared to smaller (nonsignificant) changes of $+83 \%$ for both CMIP5-early and CMIP5-late models. Of the 10 individual CMIP3 models, 3 showed a significant increase. Note that the low bias in such storms (about 20\% of the observed rate) is even more severe than the $\sim 50 \%$ low bias for category 4 and 5 storms as discussed above. Our future plans include possibly redoing these experiments with a higher-resolution version of our hurricane model (6-km inner mesh) that is currently under development, in order to improve the control simulations of these extreme events. In addition, the statistical significance of some of our results might be enhanced through longer simulations even for the present models.

Overall, our results provide further support to previous studies projecting that anthropogenic warming in the Atlantic basin over the twenty-first century will lead to fewer tropical storms and hurricanes overall but that the mean intensity of Atlantic hurricanes basinwide will increase. A projected increase in the frequency of very intense (categories 4 and 5) hurricanes is statistically significant for the CMIP3 ensemble climate change but only marginally significant for the CMIP5 early- and late-twenty-firstcentury ensembles. A robust signal is that tropical storms and hurricanes in the warmer climate are projected to have substantially higher rainfall rates than those in the current climate. The projected hurricane precipitation rate increase by the late-twenty-first-century scales roughly with the fractional increase in total precipitable water vapor content $(\sim+11 \%)$, particularly at relatively larger radii (200-400 km), but shows even larger fractional increases (order $+20 \%-30 \%$ ) near the hurricane core.

Acknowledgments. We thank Ron Stouffer and Lucas Harris of GFDL, Kerry Emanuel of MIT, and two anonymous reviewers for helpful comments on our work. We acknowledge PCMDI and the modeling groups contributing to the CMIP3 and CMIP5 model archives for generously making their model output available to the community. Funding support from the Willis Research Network for Hyeong-Seog Kim and Gabriele Villarini is gratefully acknowledged. We thank Isaac Ginis and Richard Yablonsky of the University of Rhode Island for assistance with the hurricane model ocean coupling components.

\section{REFERENCES}

Bender, M. A., I. Ginis, R. E. Tuleya, B. Thomas, and T. Marchok, 2007: The operational GFDL coupled hurricane-ocean prediction system and a summary of its performance. Mon. Wea. Rev., 135, 3965-3989.

— T. T. Knutson, R. E. Tuleya, J. J. Sirutis, G. A. Vecchi, S. T. Garner, and I. M. Held, 2010: Modeled impact of anthropogenic warming of the frequency of intense Atlantic hurricanes. Science, 327, 454-458.

Camargo, S., M. Ting, and Y. Kushnir, 2013: Influence of local and remote SST on North Atlantic tropical cyclone potential intensity. Climate Dyn., 40, 1515-1529.

Chauvin, F., J.-F. Royer, and M. Déqué, 2006: Response of hurricane-type vortices to global warming as simulated by ARPEGE-Climat at high resolution. Climate Dyn., 27, 377-399.

Chen, S. S., W. Zhao, M. A. Donelan, J. F. Price, and E. J. Walsh, 2007: The CBLAST-Hurricane program and the next-generation fully coupled atmosphere-wave-ocean models for hurricane research and prediction. Bull. Amer. Meteor. Soc., 88, 311-317.

Emanuel, K., 2005: Increasing destructiveness of tropical cyclones over the past 30 years. Nature, 436, 686-688.

— 2007: Environmental factors affecting tropical cyclone power dissipation. J. Climate, 20, 5497-5509.

—, R. Sundararajan, and J. Williams, 2008: Hurricanes and global warming-Results from downscaling IPCC AR4 simulations. Bull. Amer. Meteor. Soc., 89, 347-367.

— S. Solomon, D. Folini, S. Davis, and C. Cagnazzo, 2013: Influence of tropical tropopause layer cooling on Atlantic hurricane activity. J. Climate, 26, 2288-2301.

Gentry, M. S., and G. M. Lackmann, 2006: The sensitivity of WRF simulations of Hurricane Ivan to choice of cumulus parameterization. Preprints, 27th Conf. on Hurricanes and Tropical 
Meteorology, Monterey, CA, Amer. Meteor. Soc., P5.14. [Available online at https://ams.confex.com/ams/pdfpapers/ 108539.pdf.]

— , and - 2010: Sensitivity of simulated tropical cyclone structure and intensity to horizontal resolution. Mon. Wea. Rev., 138, 688-704.

Han, J., and H.-L. Pan, 2006: Sensitivity of hurricane intensity forecast to convective momentum transport parameterization. Mon. Wea. Rev., 134, 664-674.

Held, I. M., and M. Zhao, 2011: The response of tropical cyclone statistics to an increase in $\mathrm{CO}_{2}$ with fixed sea surface temperatures. J. Climate, 24, 5353-5364.

Hill, K. A., and G. M. Lackmann, 2011: The impact of future climate change on TC intensity and structure: A downscaling approach J. Climate, 24, 4644-4661.

Kalnay, E., and Coauthors, 1996: The NCEP/NCAR 40-Year Reanalysis Project. Bull. Amer. Meteor. Soc., 77, 437-471.

Knutson, T. R., and R. E. Tuleya, 2004: Impact of $\mathrm{CO}_{2}$-induced warming on simulated hurricane intensity and precipitation Sensitivity to the choice of climate model and convective parameterization. J. Climate, 17, 3477-3495.

,,-- W. Shen, and I. Ginis, 2001: Impact of $\mathrm{CO}_{2}$-induced warming on hurricane intensities simulated in a hurricane model with ocean coupling. J. Climate, 14, 2458-2468.

— J. J. Sirutis, S. T. Garner, I. M. Held, and R. E. Tuleya, 2007: Simulation of the recent multidecadal increase of Atlantic hurricane activity using an $18-\mathrm{km}$-grid regional model. Bull. Amer. Meteor. Soc., 88, 1549-1565.

, G. A. Vecchi, and I. M. Held, 2008: Simulated reduction in Atlantic hurricane frequency under twentyfirst-century warming conditions. Nat. Geosci., 1, 359-364, doi:10.1038/ngeo202.

_ and Coauthors, 2010: Tropical cyclones and climate change. Nat. Geosci., 3, 157-163, doi:10.1038/ngeo779.

Latif, M., N. Keenlyside, and J. Bader, 2007: Tropical sea surface temperature, vertical wind shear, and hurricane development. Geophys. Res. Lett., 34, L01710, doi:10.1029/2006GL027969.

Meehl, G. A., C. Covey, T. Delworth, M. Latif, B. McAvaney, J. F. B. Mitchell, R. J. Stouffer, and K. E. Taylor, 2007: The WCRP CMIP3 multimodel dataset: A new era in climate change research. Bull. Amer. Meteor. Soc., 88, 1383-1394.

Mendelsohn, R., K. Emanuel, S. Chonabayashi, and L. Bakkensen, 2012: The impact of climate change on global tropical cyclone damage. Nat. Climate Change, 2, 205-209.

Murakami, H., and Coauthors, 2012: Future changes in tropical cyclone activity projected by the new high-resolution MRIAGCM. J. Climate, 25, 3237-3260.

Oouchi, K., J. Yoshimura, H. Yoshimura, R. Mizuta, S. Kusumoki, and A. Noda, 2006: Tropical cyclone climatology in a global warming climate as simulated in a $20-\mathrm{km}$-mesh global atmospheric model: Frequency and wind intensity analysis. J. Meteor. Soc. Japan, 84, 259-276.

Pielke, R. A., J. Gratz, C. W. Landsea, D. Collins, M. A. Saunders, and R. Musulin, 2008: Normalized hurricane damages in the United States: 1900-2005. Nat. Hazards Rev., 9, 29-42.

Ramsay, H. A., and A. H. Sobel, 2011: Effects of relative and absolute sea surface temperature on tropical cyclone potential intensity using a single-column model. J. Climate, 24, 183-193.

Reichler, T., and J. Kim, 2008: How well do coupled models simulate today's climate? Bull. Amer. Meteor. Soc., 89, 303-311.

Shen, W., R. E. Tuleya, and I. Ginis, 2000: A sensitivity study of the thermodynamic environment on GFDL model hurricane intensity: Implications for global warming. J. Climate, 13, 109-121.
Solomon, S., D. Qin, M. Manning, M. Marquis, K. Averyt, M. B. Tignor, H. L. Miller Jr., and Z. Chen, Eds., 2007: Climate Change 2007: The Physical Science Basis. Cambridge University Press, $996 \mathrm{pp}$

Sugi, M., A. Noda, and N. Sato, 2002: Influence of global warming on tropical cyclone climatology: An experiment with the JMA global model. J. Meteor. Soc. Japan, 80, 249-272, doi:10.2151/ jmsj.80.249.

-, H. Murakami, and J. Yoshimura, 2009: A reduction in global tropical cyclone frequency due to global warming. SOLA, 5, 164 167.

Swanson, K. L., 2008: Nonlocality of Atlantic tropical cyclone intensities. Geochem. Geophys. Geosyst., 9, Q04V01, doi:10.1029/ $2007 \mathrm{GC001844.}$

Taylor, K. E., R. J. Stouffer, and G. A. Meehl, 2012: An overview of CMIP5 and the experiment design. Bull. Amer. Meteor. Soc., 93, 485-498.

Vecchi, G. A., and B. J. Soden, 2007a: Increased tropical Atlantic wind shear in model projections of global warming. Geophys. Res. Lett., 34, L08702, doi:10.1029/2006GL028905.

— change on tropical cyclone potential intensity. Nature, 450, 1066-1070, doi:10.1038/nature06423.

— , K. L. Swanson, and B. J. Soden, 2008: Whither hurricane activity? Science, 322, 687-689.

—, M. Zhao, H. Wang, G. Villarini, A. Rosati, A. Kumar, I. M. Held, and R. Gudgel, 2011: Statistical-dynamical predictions of seasonal North Atlantic hurricane activity. Mon. Wea. Rev., 139, 1070-1082.

S. Fueglistaler, I. M. Held, T. R. Knutson, and M. Zhao, 2013a: Impacts of atmospheric temperature changes on tropical cyclone activity. J. Climate, 26, 3877-3891.

, and Coauthors, 2013b: Multiyear predictions of North Atlantic hurricane frequency: Promise and limitations. J. Climate, 26, 5337-5357.

Villarini, G., and G. A. Vecchi, 2012a: North Atlantic Power Dissipation Index (PDI) and accumulated cyclone energy (ACE): Statistical modeling and sensitivity to sea surface temperature changes. J. Climate, 25, 625-637.

, and - 2012b: Twenty-first-century projections of North Atlantic tropical storms from CMIP5 models. Nat. Climate Change, 2, 604-607.

, and - 2013: Projected increases in North Atlantic tropical cyclone intensity from CMIP5 models. J. Climate, 26, 3231-3240.

,-- T. R. Knutson, M. Zhao, and J. A. Smith, 2011: North Atlantic tropical storm frequency response to anthropogenic forcing: Projections and sources of uncertainty. J. Climate, 24, 3224-3238.

Zhao, M., and I. M. Held, 2010: An analysis of the effect of global warming on the intensity of Atlantic hurricanes using a GCM with statistical refinement. J. Climate, 23, 63826393.

$\longrightarrow,-$, S.-J. Lin, and G. A. Vecchi, 2009: Simulations of global hurricane climatology, interannual variability, and response to global warming using a 50-km resolution GCM. J. Climate, 22, 6653-6678.

- - - , and G. A. Vecchi, 2010: Retrospective forecasts of the hurricane season using a global atmospheric model assuming persistence of SST anomalies. Mon. Wea. Rev., 138, 38583868 .

_ _ _ a and S.-J. Lin, 2012: Some counterintuitive dependencies of tropical cyclone frequency on parameters in a GCM. J. Atmos. Sci., 69, 2272-2283. 